University of South Florida

DIGITAL COMMONS Digital Commons @ University of @ UNIVERSITY OF SOUTH FLORIDA South Florida

2-8-2018

\title{
Campus Automated Shuttle Service Deployment Initiative
}

CUTR

Follow this and additional works at: https://digitalcommons.usf.edu/cutr_nctr

\section{Recommended Citation}

"Campus Automated Shuttle Service Deployment Initiative," National Center for Transit Research (NCTR) Report No. CUTR-NCTR-RR-2018-06, Center for Urban Transportation Research, University of South Florida, 2018.

DOI: https://doi.org/10.5038/CUTR-NCTR-RR-2018-06

Available at: https://scholarcommons.usf.edu/cutr_nctr/46

This Technical Report is brought to you for free and open access by the National Center for Transit Research (NCTR) Archive (2000-2020) at Digital Commons @ University of South Florida. It has been accepted for inclusion in Research Reports by an authorized administrator of Digital Commons @ University of South Florida. For more information, please contact digitalcommons@usf.edu. 
Final Report

\section{Campus Automated Shuttle Service Deployment Initiative}

NCTR Livability PPPR \#18

Final Report

Prepared for:

National Center for Transit Research

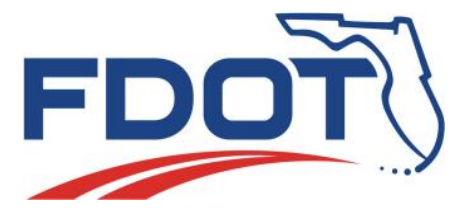

Florida Department of Transportation

June 2020

\section{CUTR USF SNIERSTT OF}




\title{
Campus Automated Shuttle Service Deployment Initiative
}

\author{
NCTR Livability PPPR \#18
}

Final Report

Prepared for:

National Center for Transit Research

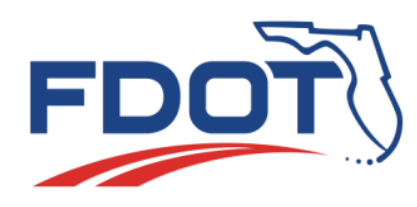

Florida Department of Transportation

Prepared by:

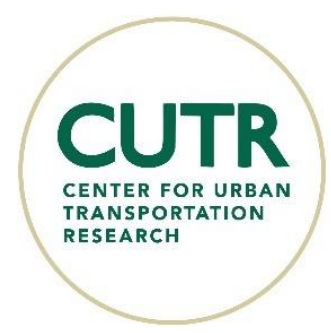

USF Center for Urban Transportation Research

Pei-Sung Lin, Ph.D., P.E., PTOE, FITE

Achilleas Kourtellis, Ph.D.

Nikhil Menon, Ph.D.

Cong Chen, Ph.D., P.E., M.ASCE

Rakesh Rangaswamy

June 2020 


\section{DISCLAIMER}

The opinions, findings, and conclusions expressed in this publication are those of the authors and not necessarily those of the State of Florida Department of Transportation. 


\section{Table of Contents}

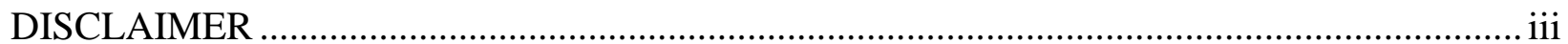

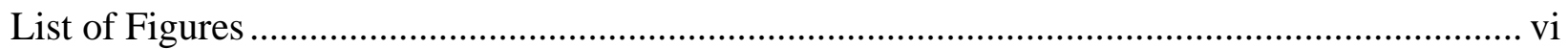

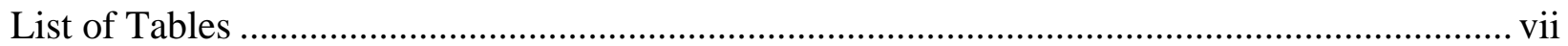

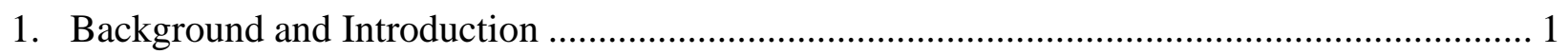

2. Preparation and Coordination of Campus Automated Shuttle Demonstration .......................... 4

2.1. Review of Technologies and Vendors of Automated/Connected Shuttle Service ............. 4

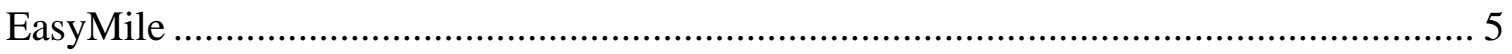

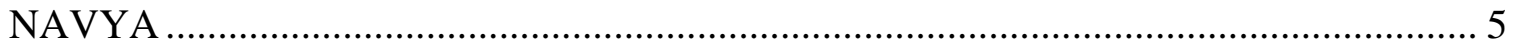

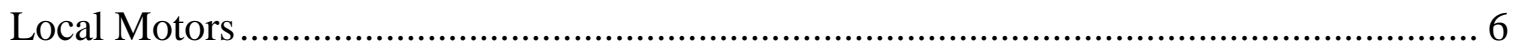

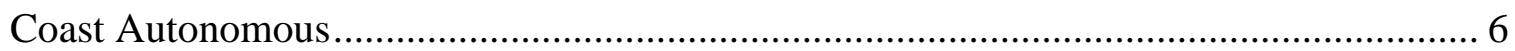

2.2. Partnering with USF and Tampa Bay Regional Stakeholders to Obtain Input.................. 7

2.3. Coordination with Automated Shuttle Vendors for Demonstration .................................... 7

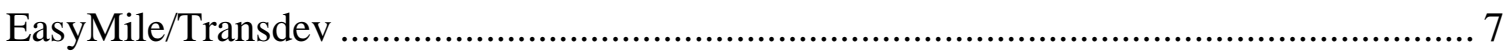

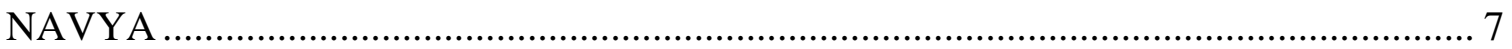

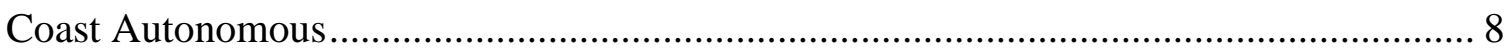

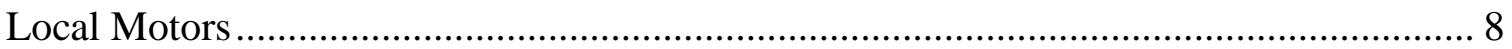

Final Selection of Automated Shuttle Vendor Candidate for Demonstration .................... 8

3. Automated Shuttle Vendor Overview - COAST Autonomous ............................................... 9

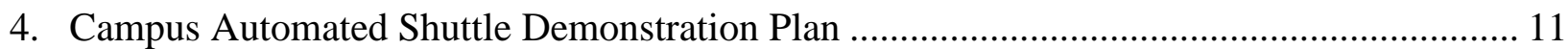

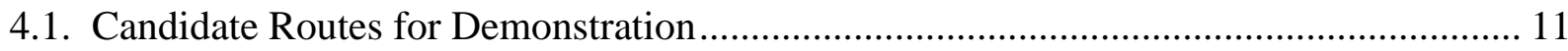

Characteristics of Demonstration Route ........................................................................... 11

Final List of Demonstration Routes............................................................................... 11

5. Development of Assessment Methods for Automated Shuttle Demonstration ....................... 16

5.1. Onboard Opinion/Feedback Survey of Automated Shuttle Riders................................... 16

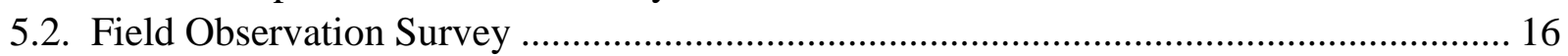

5.3. Expert Opinion Survey for Automated Shuttle Performance ............................................ 16

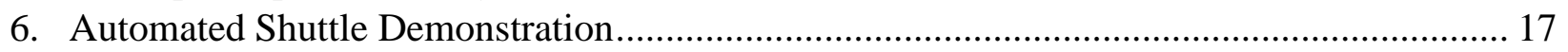

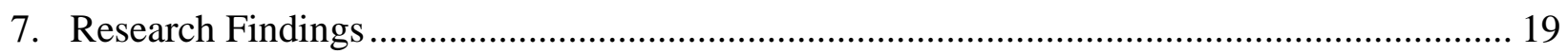

7.1. Onboard Opinion/Feedback Survey of Automated Shuttle Riders.................................. 19

Respondent Demographics ........................................................................................ 19

Current Travel Characteristics …………………………………………………... 23

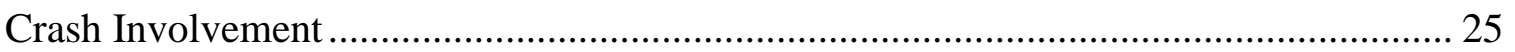

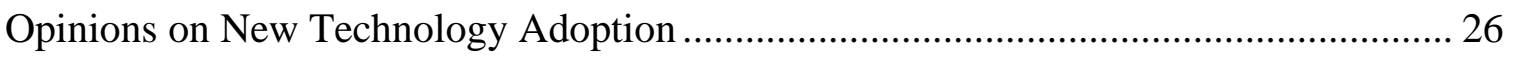

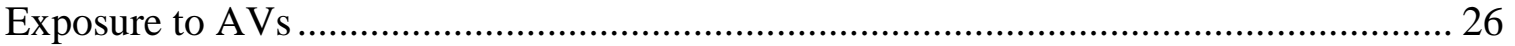

Experience Riding the Automated Shuttles ................................................................... 28

Using Automated Shuttles ......................................................................................... 29

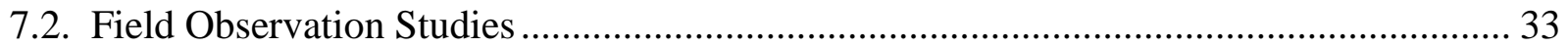

Events Observed during Field Observation ................................................................ 34

Automated Shuttle Reactions during Field Observation ................................................ 34

Pedestrian Reactions during Field Observation ............................................................ 35

Bicyclist Reactions during Field Observation ............................................................ 36 


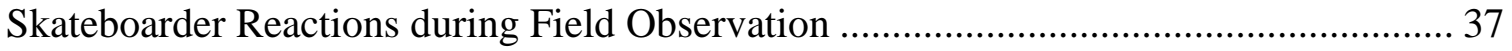

7.3. Automated Vehicle Expert Assessment....................................................................... 37

Ride Experience and Comfort during Automated Shuttle Ride................................... 38

Interactions between AV Shuttle and Other Users ........................................................ 38

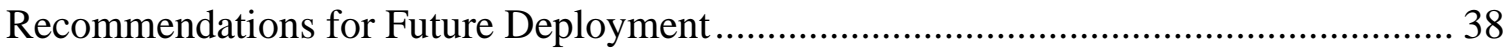

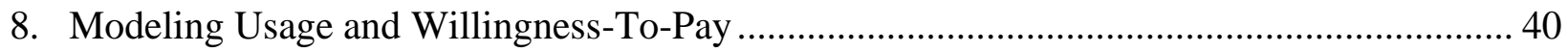

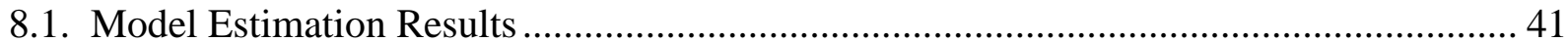

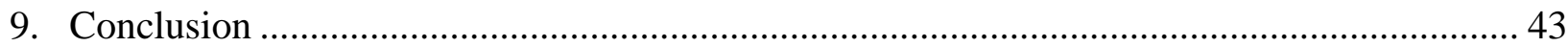

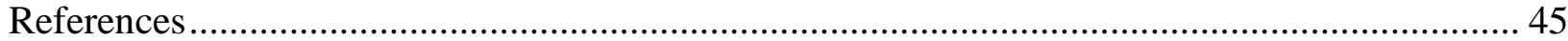

Appendix A - Onboard Survey Questionnaire .................................................................... 48

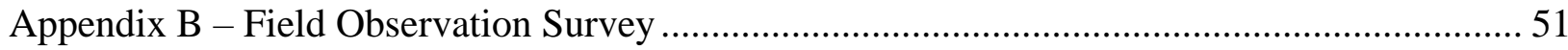




\section{List of Figures}

Figure 1 - CUTR's vision for USF connected automated vehicle testbed ................................. 2

Figure 2 - EasyMile EZ10 with ramp for passengers with reduced mobility (Source: 18) .......... 5

Figure 3 - Interior of EZ10 shuttle (Source: 19) ................................................................... 5

Figure 4 - NAVYA AUTONOM shuttle (Source: 19) .......................................................... 5

Figure 5 - Olli shuttle (Source: 21) ..................................................................................... 6

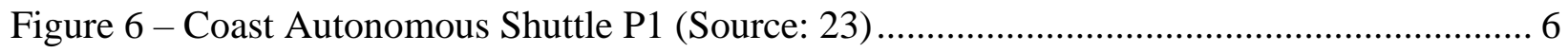

Figure 7 - COAST P1 shuttle demonstration in Times Square ................................................... 9

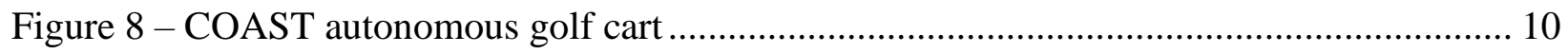

Figure 9 - CUTR research team with COAST P1 shuttle .................................................. 10

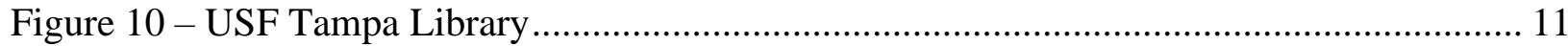

Figure 11 - Candidate Route \#1 .............................................................................. 12

Figure 12 - Candidate Route \#2 ................................................................................... 12

Figure 13 - Candidate Route \#3 ........................................................................................ 13

Figure 14 - Candidate Route \#4 ...................................................................................... 13

Figure 15 - USF Marshall Student Center (Source: 33) ...................................................... 14

Figure 16 - Candidate Route \#5 ....................................................................................... 14

Figure 17 - Candidate Route \#6 ..................................................................................... 15

Figure 18 - Candidate Route \#7 ............................................................................................. 15

Figure 19 - Selected route for automated shuttle demonstration ........................................ 17

Figure 20 - Promotional flyer for campus automated shuttle demonstration............................ 18

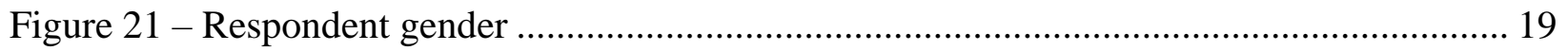

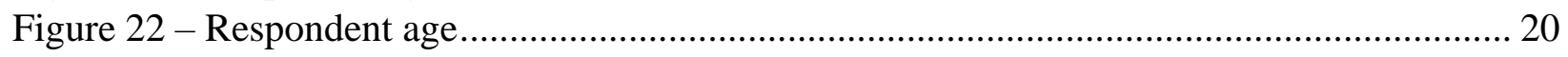

Figure 23 - Respondent annual household income ..................................................... 21

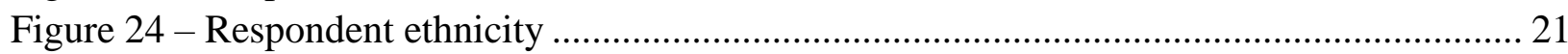

Figure 25 - Respondent race................................................................................. 22

Figure 26 - Respondent household vehicle distribution................................................... 22

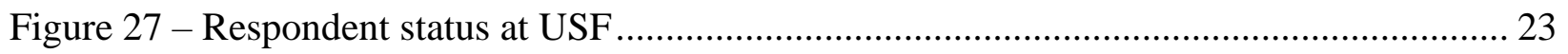

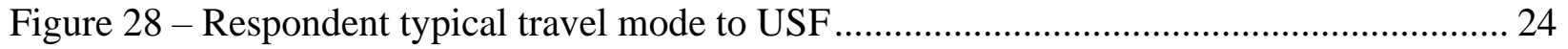

Figure 29 - Respondent typical one-way travel time to USF ................................................ 24

Figure 30 - Respondent typical one-way travel time to USF ............................................... 25

Figure 31 - Respondent crash involvement.......................................................................... 25

Figure 32 - Respondent propensity to adopt new technology ............................................ 26

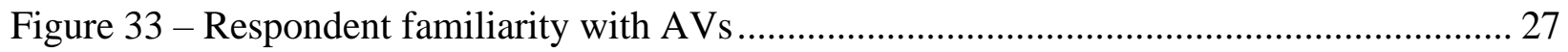

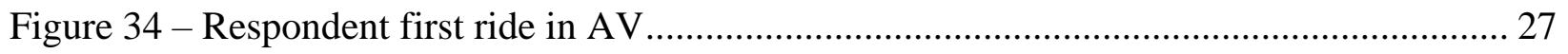

Figure 35 - Respondent overall experience riding in automated shuttle ................................. 28

Figure 36 - Respondent opinions on automated shuttle areas to improve ............................... 29

Figure 37 - Respondent opinions on use of automated shuttles ......................................... 30

Figure 38 - Respondent opinion on replacing campus trips with automated shuttles................ 31

Figure 39 - Respondent trust in automated shuttles ...................................................... 31

Figure 40 - Respondent change in trust after riding automated shuttle ................................... 32

Figure 41 - Respondent most concerning factor about automated shuttles............................. 33 
Figure 42 - Respondent least concerning factor about automated shuttles .............................. 33

Figure 43 - Events observed during automated shuttle demonstration .................................... 34

Figure 44 - Automated shuttle reactions observed during field observation ............................. 35

Figure 45 - Pedestrian interactions with automated shuttle ................................................. 36

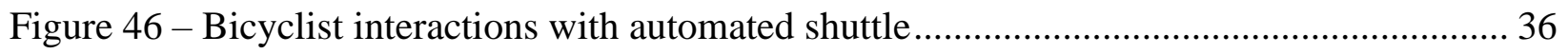

Figure 47 - Skateboarder interactions with automated shuttle ........................................... 37

\section{List of Tables}

Table 1 - Comparison of Automated Shuttle Vendor Technologies ........................................ 4

Table 2 - Binary Logit Model Estimation of Respondents' Likelihood to Use Automated Shuttles for Some/All Campus Trips...................................................................41

Table 3 - Binary Logit Model Estimation of Respondents' Willingness to Pay to Use Automated

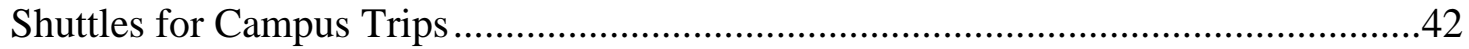




\section{Background and Introduction}

Public transit systems, including transit bus and shuttle service, have been advocated to address reducing traffic congestion, fuel consumption, emissions, traffic crash risk, personal vehicle use, and overall associated loss of productivity. Most mid-size and large open-campus universities have courtesy shuttle or bus service as an important mode of transportation around campus and in nearby vicinities. Given on-campus traffic conditions, traffic congestion between classes, the nature of short-distance trips within or around campus, and difficulty with finding parking spaces, automated shuttle service has been recognized as a promising solution to alleviate these problems.

Automated shuttle/bus systems have been designed or are under development by peer high-tech companies (e.g., EasyMile, NAVYA, Meridian) to cover short distances and pre-defined routes in multi-use environments. The innovative automated shuttle/bus systems currently on the market are capable of navigation, path planning and control, obstacle detection, or/and crash avoidance and have been successfully showcased in multiple scenarios. Most investment in and testing of autonomous shuttles in the past were in Europe; two recent autonomous shuttle projects were conducted on college campuses, one at the Swiss Federal Institute of Technology in Lausanne, Switzerland, in 2015 and one at Wageningen University in the Netherlands in 2016. In the past couple of years, the demonstration or testing of autonomous shuttles has begun to draw attention in the US.

The University of South Florida (USF) is a major US university with approximately 50,000 students enrolled, and USF's Bull Runner bus service has an annual ridership of more than 1.3 million around the Tampa campus and nearby vicinities. The Hillsborough County Metropolitan Planning Organization (MPO) proposed a USF Area Multimodal Study in its 2040 Long Range Transportation Plan (1) and has been consistently working on multiple transit circulator studies in past years to improve safety and mobility in the USF area. USF's Center for Urban

Transportation Research (CUTR) has been partnering with and supporting the Hillsborough County MPO, the Tampa Hillsborough Expressway Authority (THEA), and Hillsborough Area Regional Transit (HART) on a wide variety of innovative research projects regarding connected vehicles and automated transit vehicles in the Tampa area. The transportation needs on the USF Tampa campus, strong partnerships in Tampa Bay area, and CUTR's experience provide full support for the proposed campus automated shuttle service deployment initiative.

CUTR's vision for a USF connected automated vehicle (AV) testbed, shown in Figure 1, includes 1) an AV environment, 2) a connected, prioritized Bull Runner, 3) safe and connected bicycles, 4) connected optimized traffic signals, and 5) connected wayfinding. This vision could lead the USF Tampa campus to become a major campus AV testbed in the US, and a campus automated shuttle service demonstration could begin this vision. 


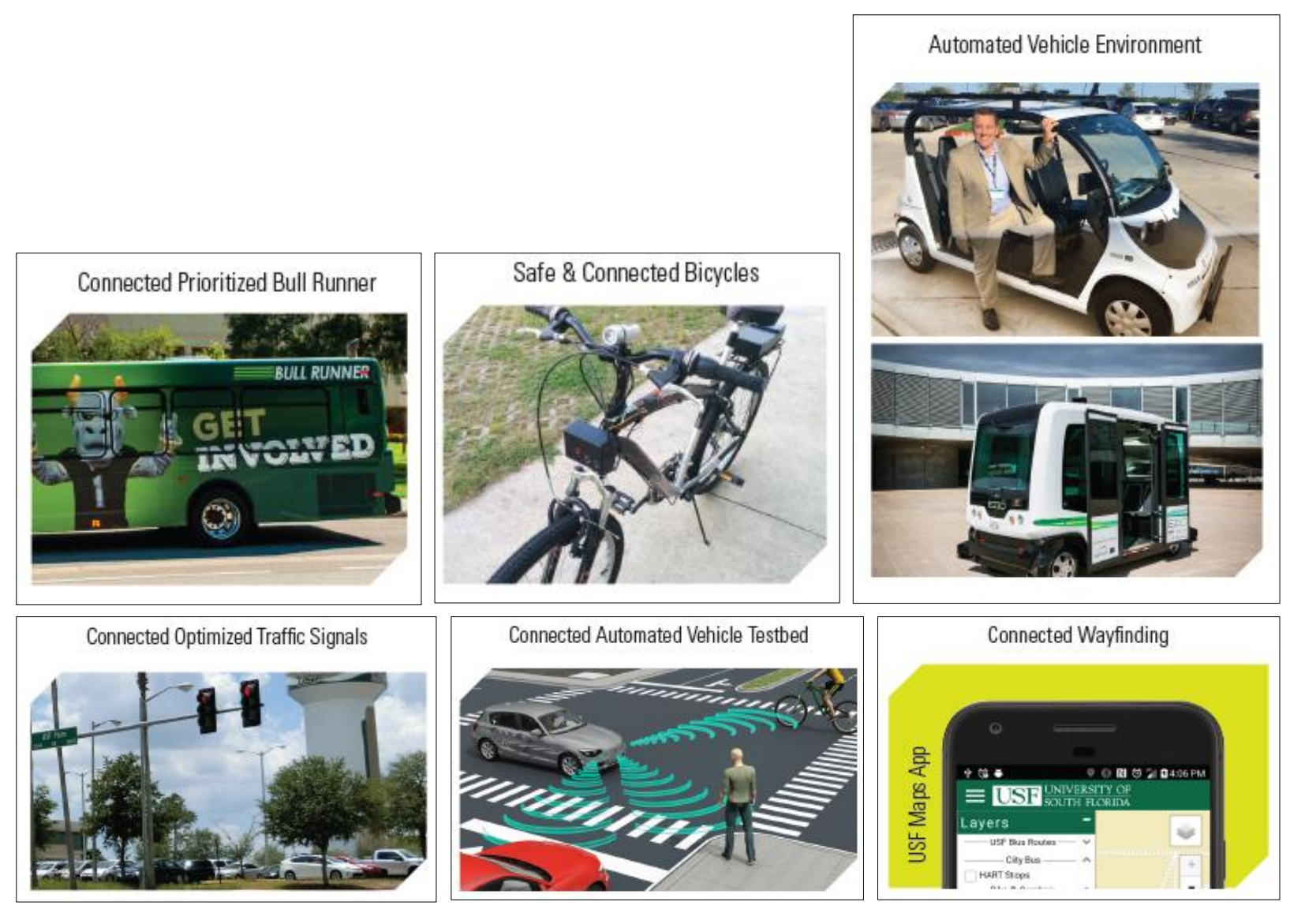

Figure 1-CUTR's vision for USF connected automated vehicle testbed

As autonomous shuttles are new to the USF Tampa campus community, a demonstration and introduction of autonomous shuttles to students, faculty, and staff that allows them to have actual riding experience are valuable and useful. The major benefits include but are not limited to 1) obtaining valuable input, comments, and support from potential users and stakeholders for future deployment on the USF Tampa campus, 2) technical involvement, assessment, and recommendations from autonomous vehicle (AV) experts on the USF Tampa campus and in the Tampa Bay region, and 3) support for detailed planning, designing, pilot testing, and implementation.

This is very timely, as AV technologies have the potential to significantly change the way people travel and has several potential benefits, such as enhanced safety (2), improved fuel efficiency, and more productive use of travel time. On the other hand, the most cited concerns are equipment failure, liability, and software security and privacy issues regarding data sharing (see (3) for a complete discussion on this topic). Also, there is still some uncertainty with regard to public acceptance and adoption of AVs. Past research shows that not all new technologies are immediately accepted by the general public (4-6), and there are potentially important psychological and behavioral tendencies that will affect peoples' attitudes and opinions toward AVs and their eventual adoption (7). There has been very limited research on automated shuttles 
as a transportation mode, and a majority of studies focusing on public opinions, acceptance, and adoption of AVs $(2,3,8-11)$ did not involve riding in an automated vehicle/shuttle. Physical experience with AVs is an important step, as it could potentially avoid negative respondent opinions based on a flawed understanding of the technology and its current development (12).

Most existing studies on automated shuttles that are based on a physical riding experience (1316) rate the overall experience as positive. Other aspects such as willingness to pay for automated shuttles have been investigated in very limited detail and have produced mixed feedback from most survey respondents (17). This study aimed to add to the growing body of literature on public opinion and acceptance of automated shuttles. A one-week demonstration of an automated shuttle (Coast Autonomous P1) on the USF-Tampa campus was conducted to elicit respondent feedback on their experience with riding in an automated shuttle. 


\section{Preparation and Coordination of Campus Automated Shuttle Demonstration}

The first task in the campus automated shuttle deployment initiative involved the following three subtasks in the project scope:

- Subtask A - Conduct comprehensive review of technologies and vendors of automated/ connected shuttle service.

- Subtask B - Partner with USF and Tampa Bay regional stakeholders to obtain input.

- Subtask C - Coordinate with vendor candidates for a campus automated/connected shuttle service demonstration.

\subsection{Review of Technologies and Vendors of Automated/Connected Shuttle Service}

A comprehensive review of various automated/connected shuttle service technologies was conducted during the initial stages of the project to select the most appropriate vendor candidate. Each was considered thoroughly based on onboard technology and package. The vendors considered for the project were:

- EasyMile

- NAVYA

- Local Motors

- Coast Autonomous

Detailed specifications and information for each of these technologies is provided in Table 1.

Table 1 -Comparison of Automated Shuttle Vendor Technologies

\begin{tabular}{|c|c|c|c|c|}
\hline Specifications & $\begin{array}{c}\text { EasyMile } \\
\text { (EZ10) }\end{array}$ & $\begin{array}{c}\text { NAVYA } \\
\text { (AUTONOM) }\end{array}$ & $\begin{array}{c}\text { Local Motors } \\
\text { (Olli) }\end{array}$ & $\begin{array}{c}\text { Coast Autonomous } \\
\text { (P1) }\end{array}$ \\
\hline Capacity & $12-15$ & $\begin{array}{c}15 \text { (11 sitting, } 4 \\
\text { standing) }\end{array}$ & 10 & 14 \\
\hline Cruising speed & $20 \mathrm{~km} / \mathrm{h}$ & $25 \mathrm{~km} / \mathrm{h}$ & $20 \mathrm{~km} / \mathrm{h}$ & $25 \mathrm{~km} / \mathrm{h}$ \\
\hline Maximum speed & $45 \mathrm{~km} / \mathrm{h}$ & $45 \mathrm{~km} / \mathrm{h}$ & $40 \mathrm{~km} / \mathrm{h}$ & $40 \mathrm{~km} / \mathrm{h}$ \\
\hline Air-conditioning & Yes & Yes & Yes & Yes \\
\hline Length & $3.928 \mathrm{~m}$ & $4.75 \mathrm{~m}$ & $3.92 \mathrm{~m}$ & $3.96 \mathrm{~m}$ \\
\hline Width & $1.986 \mathrm{~m}$ & $2.11 \mathrm{~m}$ & $2.05 \mathrm{~m}$ & $1.83 \mathrm{~m}$ \\
\hline Height & $2.750 \mathrm{~m}$ & $2.65 \mathrm{~m}$ & $2.50 \mathrm{~m}$ & $2.44 \mathrm{~m}$ \\
\hline Wheelbase & $2.800 \mathrm{~m}$ & N/A & $2.526 \mathrm{~m}$ & N/A \\
\hline Empty weight & $1700 \mathrm{~kg}$ & $2400 \mathrm{~kg}$ & $1800 \mathrm{~kg}$ & N/A \\
\hline Gross weight & $2750 \mathrm{~kg}$ & $3450 \mathrm{~kg}$ & $2600 \mathrm{~kg}$ & N/A \\
\hline Charge time & 7 hours & 4 hours & 2 hours & N/A \\
\hline $\begin{array}{l}\text { Average } \\
\text { autonomy }\end{array}$ & $\sim 12$ hours & $\sim 9$ hours & N/A & $\sim 10$ hours \\
\hline $\begin{array}{l}\text { Onboard } \\
\text { technology }\end{array}$ & $\begin{array}{c}\text { Cameras, LIDAR, } \\
\text { sensors, IBM } \\
\text { Watson }\end{array}$ & $\begin{array}{l}\text { GNSS antenna, } \\
\text { cameras, LIDAR } \\
\text { sensors }\end{array}$ & N/A & $\begin{array}{l}\text { LIDAR, sensors, } \\
\text { stereo camera, GPS, } \\
\text { V2X technology }\end{array}$ \\
\hline Steering/pedals & No & No & No & No \\
\hline Vehicle cost & $\sim \$ 250,000$ & $\sim \$ 225,000$ & N/A & N/A \\
\hline Operating cost & $\sim \$ 35,000$ & $\sim \$ 100,000$ & N/A & $\sim \$ 15,000$ \\
\hline
\end{tabular}




\section{EasyMile}

EasyMile is a global leader that supplies smart mobility solutions and autonomous technologies, developing software that enables automation for various transportation platforms and a powerful in-house fleet management solution for autonomous vehicles and providing smart mobility solutions for transporting passengers in private/public, urban/rural settings. EasyMile was one of the two vehicle manufacturers for the EU-sponsored CityMobil2 project (18).

EasyMile's EZ10, shown in Figures 2 and 3, began operations in 2016 and now operates in 19 countries with 90 deployments and more than 75,000 miles traveled (19). The most common applications of the EZ10 have been in retirement homes, city centers, university campuses, and theme parks/cultural sites. The EZ10 is currently the only autonomous shuttle that is wheelchairfriendly. It is $100 \%$ electric and has no steering wheel or pedal, does not require additional infrastructure, and can connect to smart infrastructure (such as traffic lights). For navigation, the vehicle uses a combination of cameras, LIDAR, and differential GPS (19).

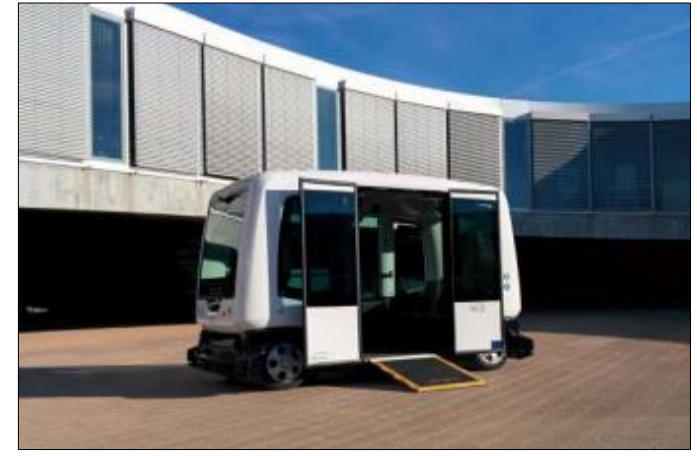

Figure 2 - EasyMile EZ10 with ramp for passengers with reduced mobility

(Source: 18)

\section{NAVYA}

NAVYA assists cities and private sites around the world with improving their transportation needs with its autonomous, driverless, and electric solutions. NAVYA is based out of Lyon, France, and started development of driverless shuttles in 2015 with its first product, ARMA (19). As of November 2017, NAVYA had a global presence with 170+ employees and one of the most experienced research and development (R\&D) teams in the world with more than 240,000 engineering man-hours (20). It has operations in multiple countries across the world, with a total of 60 deployments. NAVYA developed the AUTONOM as its flagship shuttle, as shown in

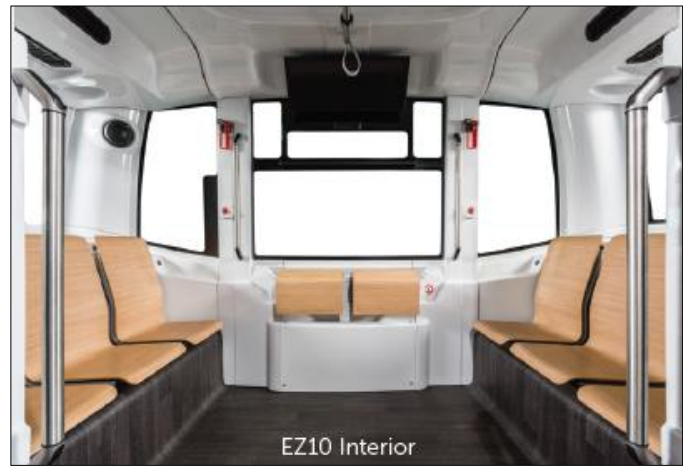

Figure 3 - Interior of EZ10 shuttle (Source: 19)

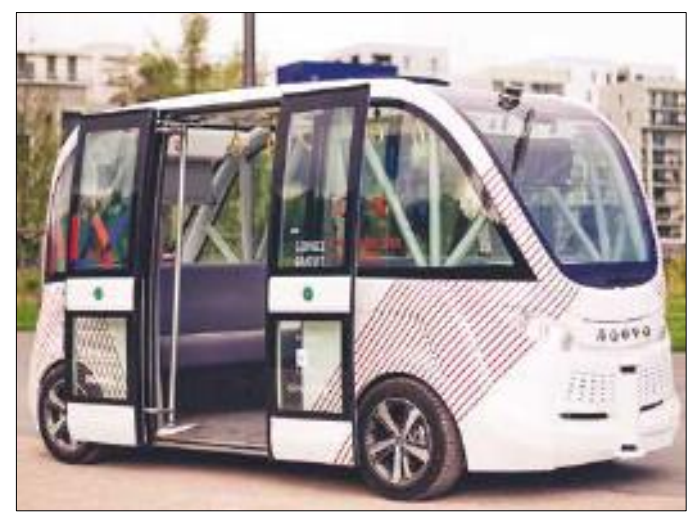

Figure 4 - NAVYA AUTONOM shuttle (Source: 19) 
Figure 4, guaranteeing autonomous transport performance as well as a comfortable trip for the first/last mile. Like the EZ10, the AUTONOM has no steering wheel or pedals and uses effective guidance and detection systems that combine various technologies, including LIDAR, GPS, odometer, and stereovision camera. LIDAR is used for obstacle detection and creating 3-D cartography, vehicle location is accomplished by GPS, speed determination is done by an odometer, and the camera is for obstacle detection and analysis of the environment (19).

\section{Local Motors}

Local Motors is an American motor vehicle manufacturing company focusing on low-volume manufacturing of open source motor vehicle designs using multiple micro-factories. Founded in 2007, Local Motors entered the driverless shuttle arena with its electric autonomous shuttle, Olli, as shown in Figure 5. Built in coordination with IBM, it has IBM Watson technology installed to provide a personalized experience for riders (21) and is the only driverless shuttle currently manufactured using additive manufacturing

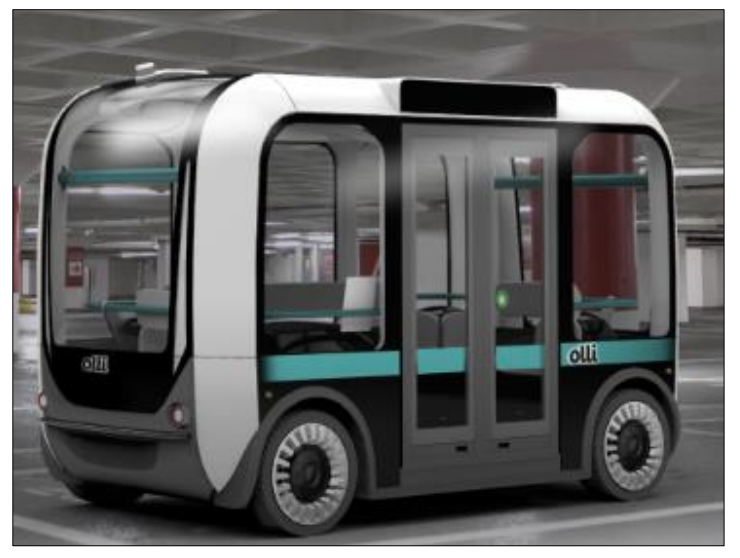

Figure 5-Olli shuttle (Source: 21) techniques such as 3D printing. Las Vegas and a municipality in Denmark debuted Olli on their roadways in 2016 and 2017, respectively (22). Multiple sensors on the shuttle see in all directions, and the inbuilt software classifies objects such as cars, pedestrians, and bicyclists and uses sophisticated algorithms to detect the speed and trajectory of other vehicles and make proactive decisions regarding navigation.

\section{Coast Autonomous}

Coast Autonomous (COAST) is a software and technology company providing Transportation-as-a-Service (TaaS) solutions to cities, theme parks, campuses, airports, and other low-speed environments using a variety of vehicles equipped with $\mathrm{AV}$ technology. Based in Pasadena, California, COAST's team comprises experts that led the only European team in the DARPA Grand Challenges in 2005 and 2007. Its first low-speed, self-driving shuttle, developed in 2010, completed 60 demonstrations in 7

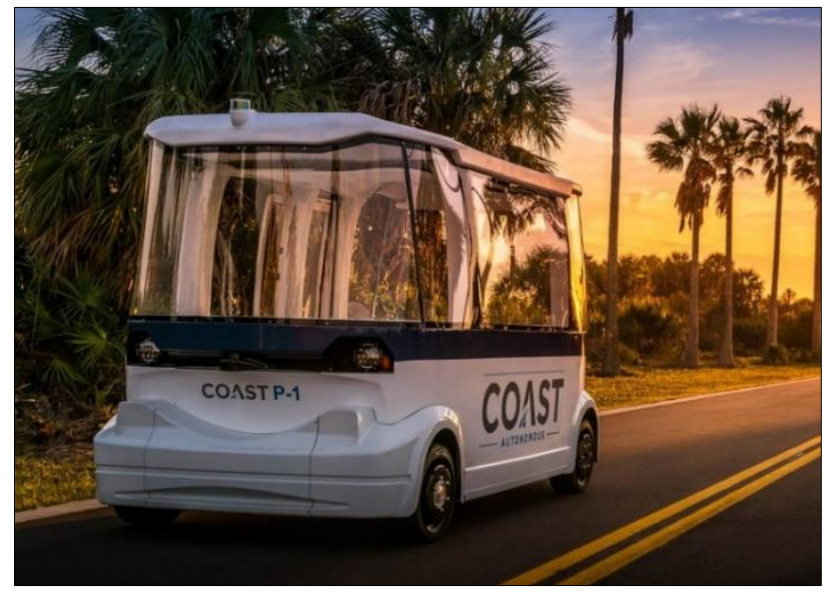

Figure 6-Coast Autonomous Shuttle P1 (Source: 23) countries (23). 
COAST's complete automation provides solutions for vehicle manufacturers and transport operators focusing on mobility in low-speed environments (up to $25 \mathrm{mph}$ ). Its flagship shuttle, the P1, as shown in Figure 6, is a bi-directional vehicle equipped with LIDAR sensors, stereo cameras, GPS, and V2X technology to transport passengers during daytime hours. The COAST system works by 3D mapping the entire site in which the vehicle operates and then programming vehicles to learn the entire network of possible routes within the environment. Once the vehicle learns the environment, the COAST software transforms the vehicle into a driverless shuttle to provide route-based or on-demand service (23).

\subsection{Partnering with USF and Tampa Bay Regional Stakeholders to Obtain Input}

Input from USF and Tampa Bay regional stakeholders was sought in an initial meeting held at CUTR on April 19, 2018. The project team presented the latest developments of the project, including progress under Task 1. Specific input also was sought on the timing of the one- or twoweek on-campus demonstration (Task 3 ) to be held later.

\subsection{Coordination with Automated Shuttle Vendors for Demonstration}

After conducting an extensive review of automated shuttle vendor candidates, the project team contacted vendor representatives to set up initial brainstorming sessions with each, as described below.

\section{EasyMile/Transdev}

The project team contacted Lauren Issac, Director of Business Initiatives (25), who handed over communications to Joseph Holmes, Sales Director for Easy Mile North America (26). Preliminary discussions regarding the potential of an automated shuttle deployment on the USF campus were held via email. After assessing the project's needs, Mr. Holmes recommended that the project team contact Andrew Chatham, Director of Product Development at Transdev, with whom the project team held an initial round of discussions (via email) (27). Transdev is a French-based international private/public transit operator working with multiple automated shuttle manufacturers in the US. During a subsequent teleconference call, the two parties agreed to continue communications regarding a potential small-scale demonstration in the Tampa Bay region in August; however, Transdev's proposed rate for a one- or two-week campus demonstration exceeded the project's budget set aside for deployment.

\section{NAVYA}

The project team contacted Aaron Foster at NAVYA (28), who forwarded a request for a campus demonstration to Tim Schock (29). Several rounds of discussions were held via email and teleconference to discuss the specifics of the project/on-campus demonstration. During a subsequent face-to-face meeting at CUTR, the prospects of a shuttle deployment, the characteristics of a good route, and the capabilities of NAVYA's automated shuttles were 
discussed. NAVYA's proposed rate for a campus demonstration also exceeded the project's budget set aside for deployment.

\section{Coast Autonomous}

The project team contacted Adrian Sussmann, Managing Director of Coast Autonomous, also referred as COAST (30), who, after a brief discussion through e-mail, met at CUTR to discuss and evaluate possible routes for the deployment and other specifics regarding the on-campus demonstration. COAST determined a rate for a one- or two-week campus deployment that was within the project's budget for deployment. Both parties further discussed a path for next steps, including a test ride on the COAST Shuttle P1 in in St. Petersburg, Florida.

\section{Local Motors}

Local Motors was contacted regarding a proposed demonstration on the USF campus; Taylor Gygi, Customer Relations Manager at Local Motors (31), responded, and the specifics of the oncampus demonstration were discussed. Local Motors undertakes only projects of six-month duration, and its proposed rate for a demonstration project far exceeded the project's budget for deployment.

\section{Final Selection of Automated Shuttle Vendor Candidate for Demonstration}

After discussions with all vendor candidates, the project team selected COAST for the one- or two-week on-campus demonstration. CUTR and COAST worked closely on plan development and demonstration preparation. 


\section{Automated Shuttle Vendor Overview - COAST Autonomous}

COAST is a self-driving mobility company with "best-in-class" software focused on providing AV solutions in low-speed environments (campuses, cities, airports, etc.). Since 2012, members of the COAST team have successfully run more than 60 trials in 7 countries and safely transported more than 120,000 passengers, including its successful demo in Times Square in New York City, as shown in Figure 7. COAST's flagship autonomous vehicle is the COAST P1, capable of seating 10-14 passengers. The P1 is fitted with state-of-the-art onboard technology including LIDAR, sensors, a stereo camera, GPS, and V2X technology for navigation. It has no steering wheel or pedals.

Extensive meetings were conducted with COAST, including an on-site demonstration of the P1 shuttle attended by members of the research team in St. Petersburg, as shown in Figures 8 and 9. Based on these discussions, a brief plan for a campus demonstration at the USF Tampa campus was proposed.
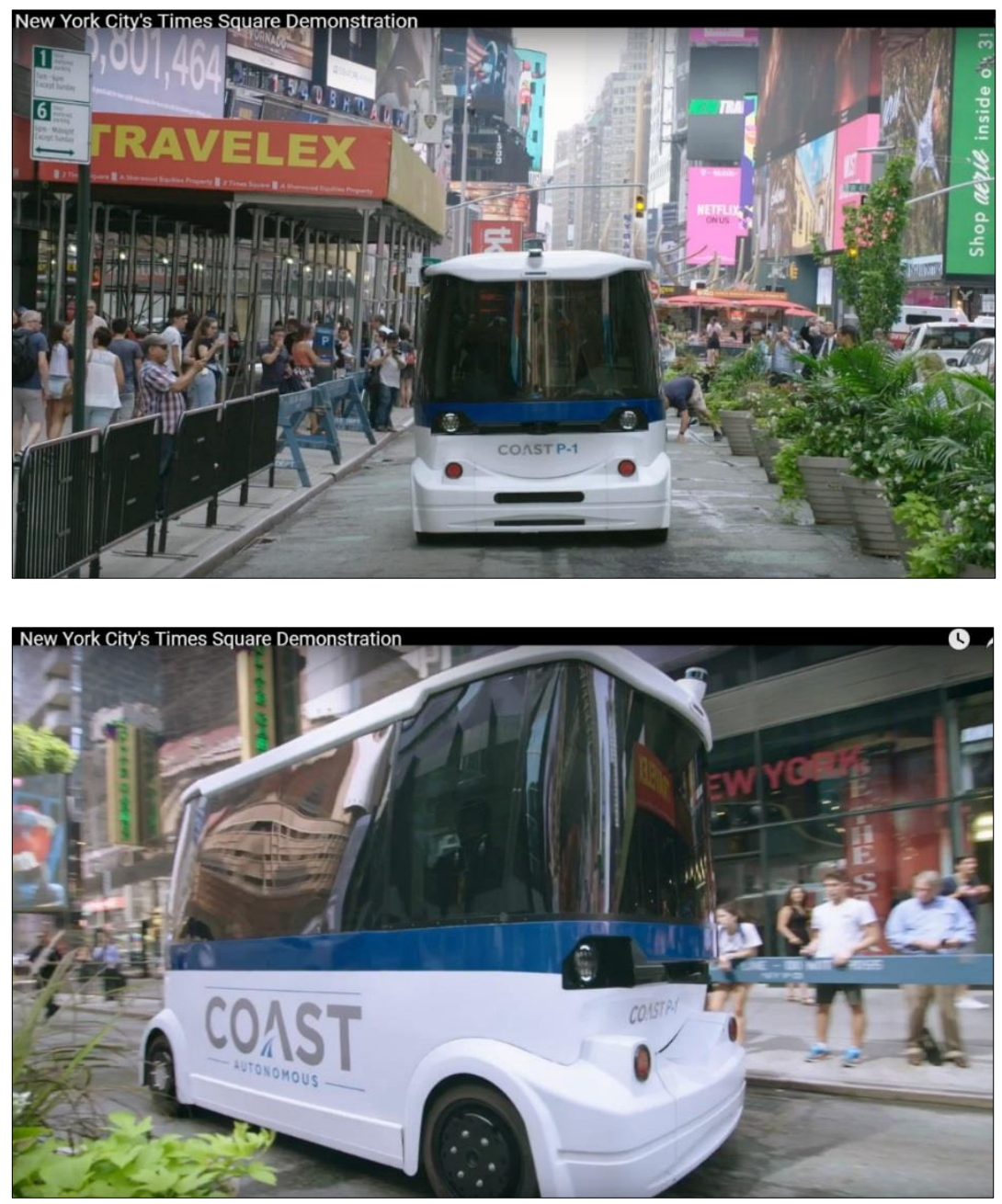

Figure 7 - COAST P1 shuttle demonstration in Times Square 


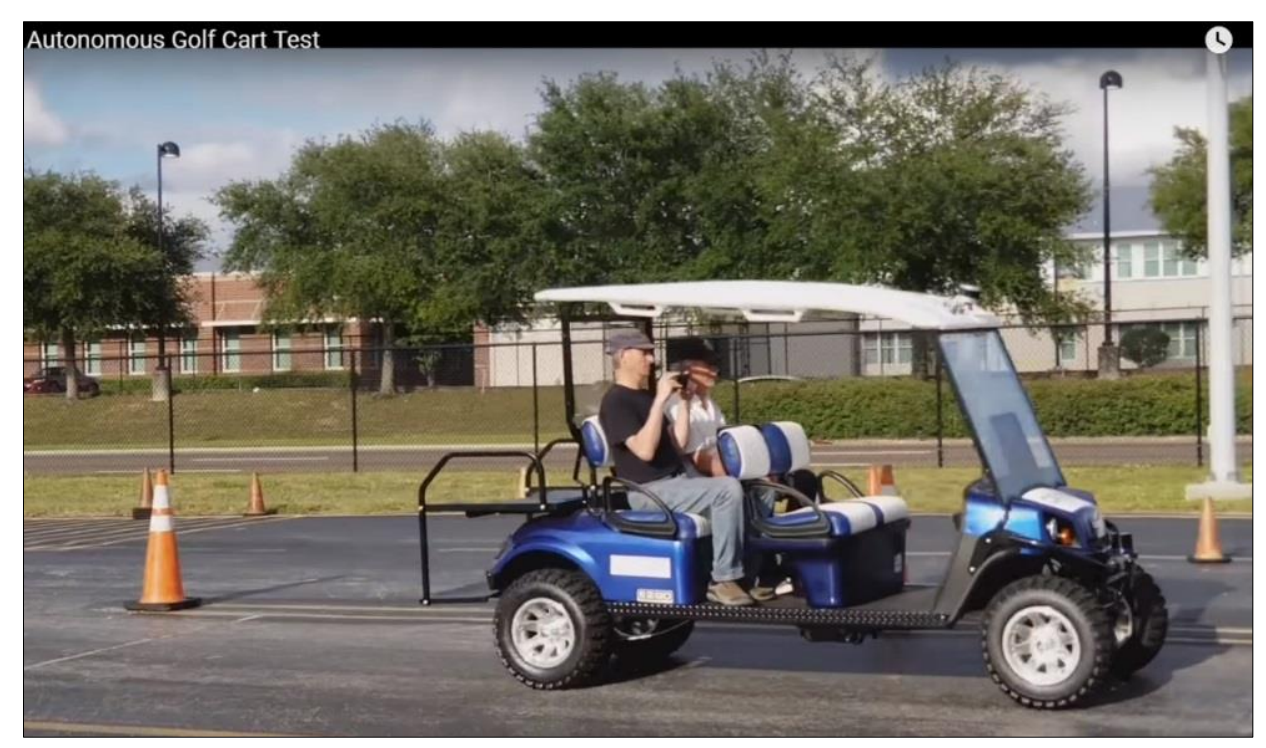

Figure 8-COAST autonomous golf cart

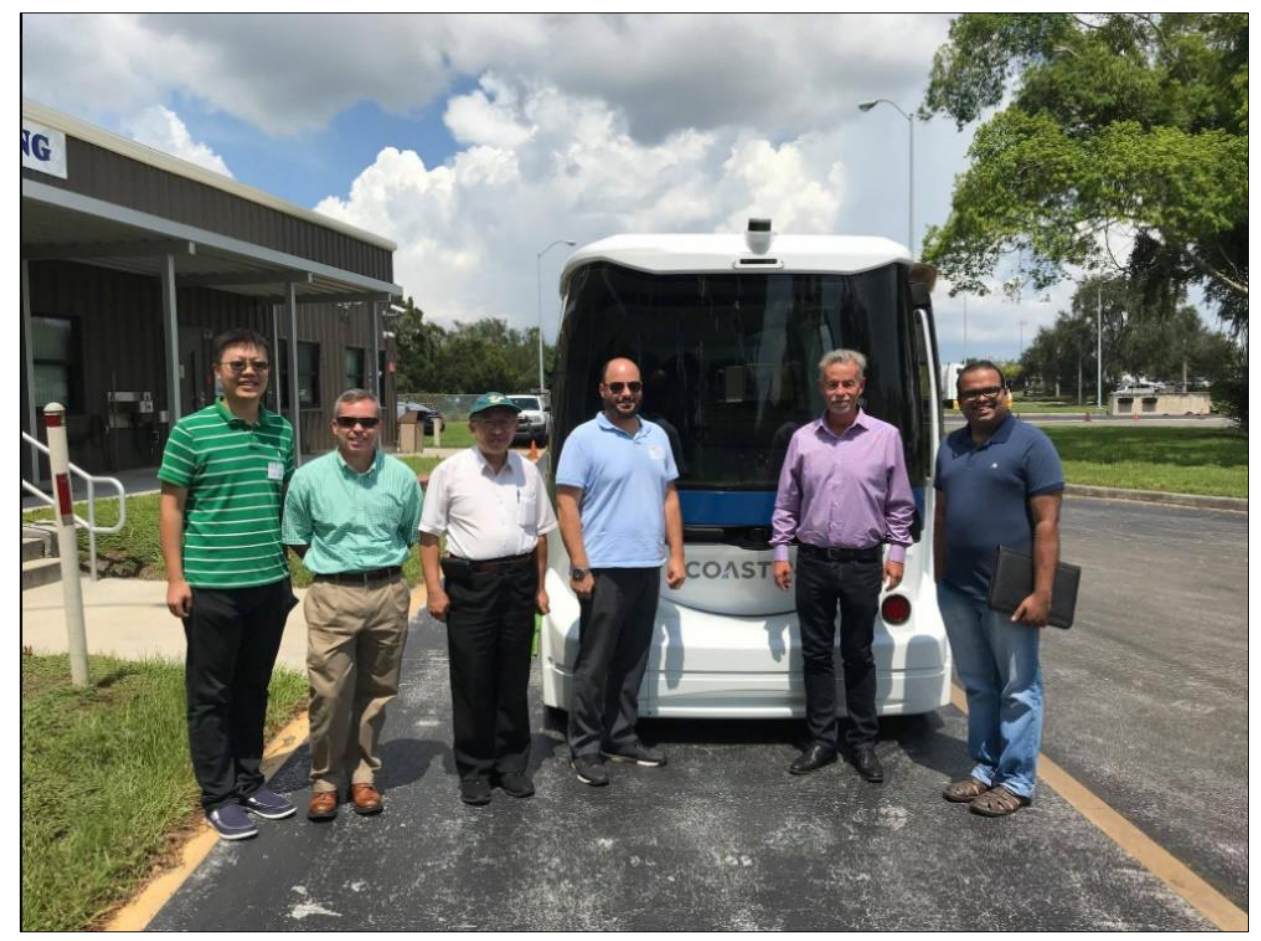

Figure 9-CUTR research team with COAST P1 shuttle 


\section{Campus Automated Shuttle Demonstration Plan}

\subsection{Candidate Routes for Demonstration}

To conduct the campus automated shuttle demonstration, the CUTR and COAST teams studied 10 potential routes on campus, which were reduced to 7 based on assessment of routes and characteristics that candidate routes needed to satisfy. The criteria for a demonstration route are described in the following paragraphs.

\section{Characteristics of Demonstration Route}

Routes were proposed for the automated shuttle demonstration based on scheduled campus activities, campus traffic features, and the functional capabilities of the automated shuttle regarding left/right turn capability, interactions with existing traffic, etc. Based on discussions with all project stakeholders, the project team concluded that an appropriate automated shuttle route should have, but not be limited to, the following features (30):

- Less than 2 miles in length

- Traffic lights, where present, capable of vehicle-to-infrastructure (V2I) communication

- Minimal obstructions that could block lines of sight

- Roadways with posted speed limits of $25 \mathrm{mph}$ or less

- Right turns preferred over left turns

\section{Final List of Demonstration Routes}

Based on the discussions with COAST and the route assessments, CUTR determined that the best campus locations for the automated shuttle demonstration would be near USF Library, as shown in Figure 10, or the Marshall Student Center, as shown in Figure 15, because of their high volume of student traffic and their relatively central location to major points on campus. The final list also included a backup shuttle route near the USF Research and Innovation area.

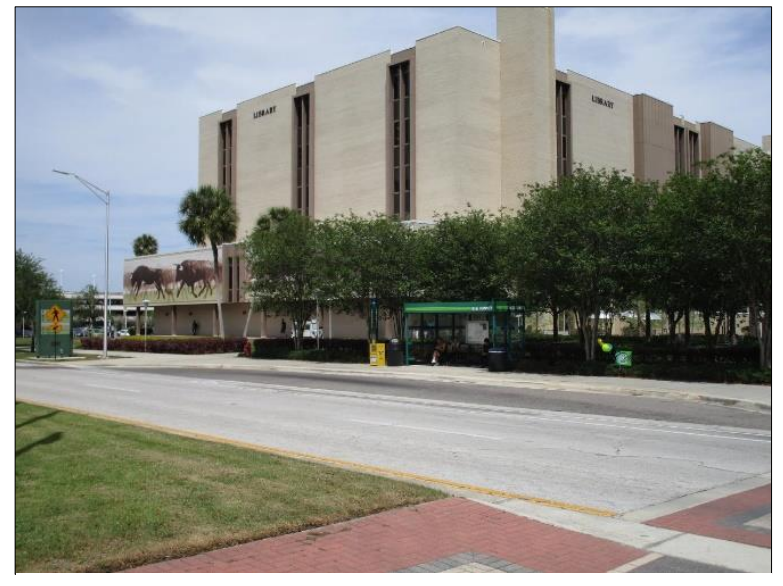

Figure 10 - USF Tampa Library

\section{USF Library}

Several routes were proposed for the campus demonstration near the USF Library. The central location of the Library, with access to several parking lots and a parking facility that attracts a large amount of traffic and pedestrian volumes, made it an ideal location for the demonstration. Routes proposed were as follows:

- Route \#1 - a simple roundtrip route ( 0.25 miles) in Parking Lot 1 north of the Library with only right-turn behavior, as shown in Figure 11. The route was proposed to test the 
shuttle's turning capability and its capability in detection and reaction (slow down, stop etc.) with respect to other vehicles or pedestrians.

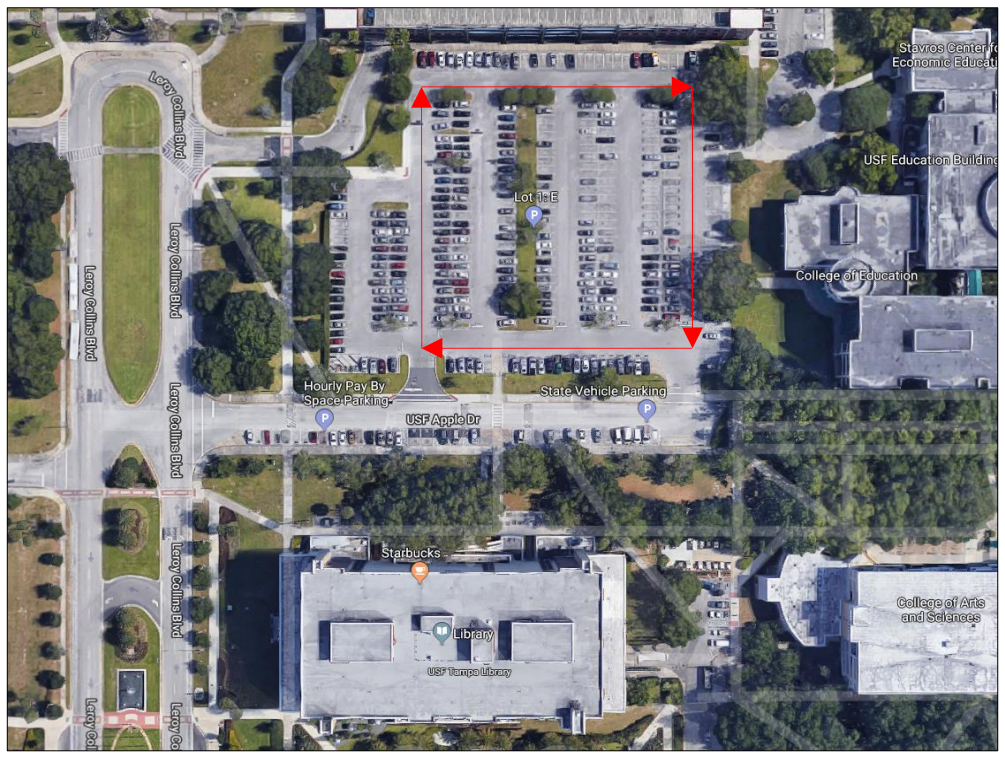

Figure 11 - Candidate Route \#1

- Route \#2 - a more complex roundtrip route (0.63 miles) that crosses Parking Lot 1 north of the Library and Leroy Collins Boulevard west of the Library, as shown in Figure 12. This route was proposed to comprehensively test the shuttle's capability for turning, speed control, communications, detection, and reaction with other vehicles and pedestrians.

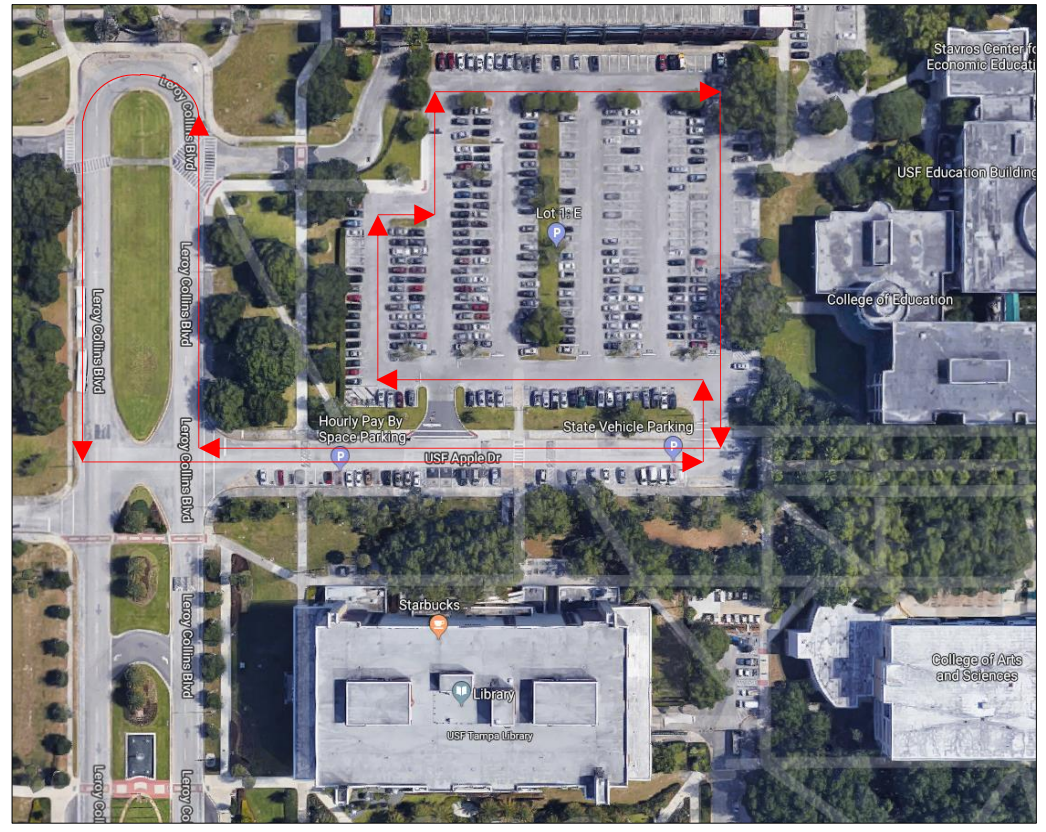

Figure 12 - Candidate Route \#2 
- Route \#3 - a round trip loop (0.23 miles) that starts on USF Apple Drive, moves into Parking Lot 1, then comes out of Parking Lot 1 onto USF Apple Drive. As shown in Figure 13. This route was proposed to test the shuttle's capability regarding turning, speed control, detection, and reaction with other vehicles and pedestrians.

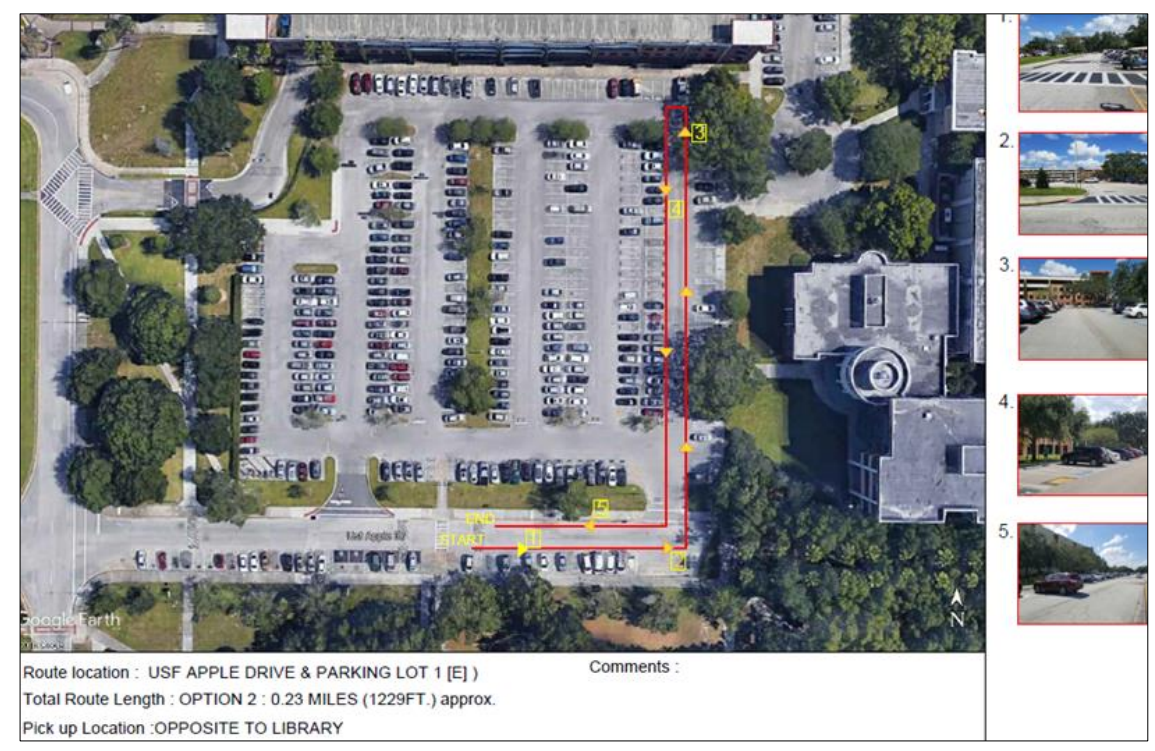

Figure 13 - Candidate Route \#3

- Route \#4 - a roundtrip loop (0.45 miles) that starts at the start of the pedestrian walkway between the USF Library and the USF Recreation Center and proceeds east to the turnstiles near the Recreation Center, then back to the start location, as shown in Figure 14. This route was proposed to test the shuttle's capabilities regarding speed control, detection, and reaction with pedestrians, bicyclists, and skateboarders.

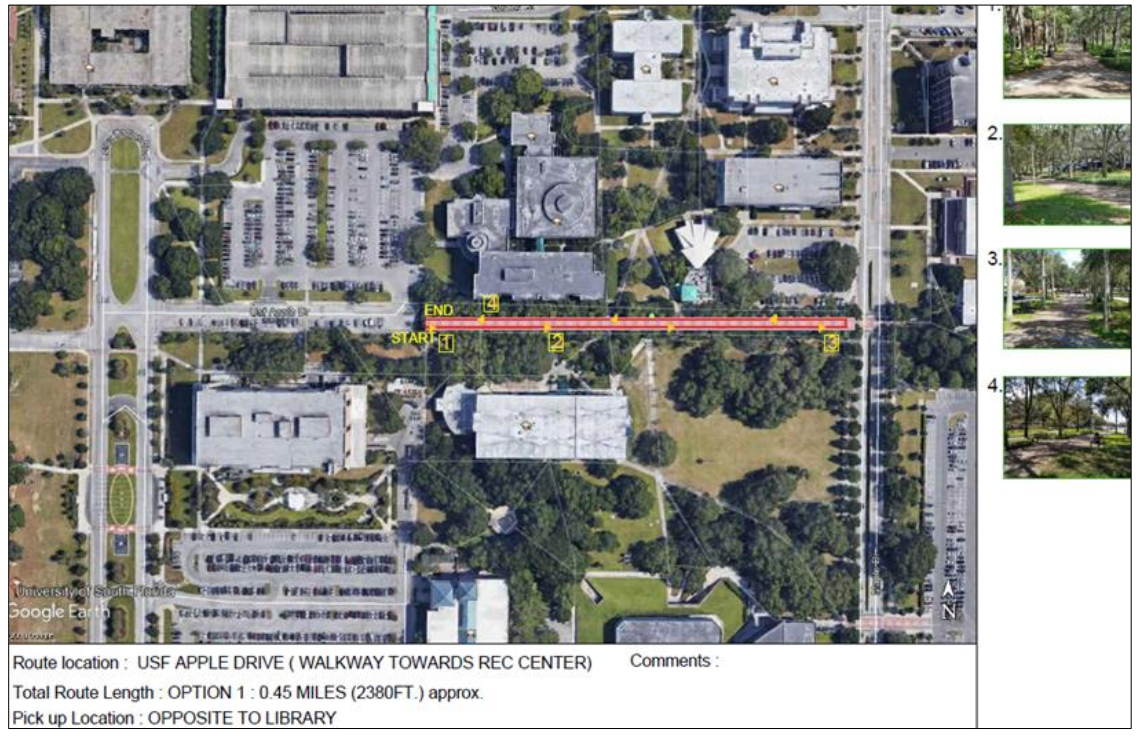

Figure 14 - Candidate Route \#4 


\section{USF Marshall Center}

The USF Marshall Student Center, as shown in Figure 15, was another possible venue for the demonstrations because of the large volume of pedestrians and vehicular traffic in the area.

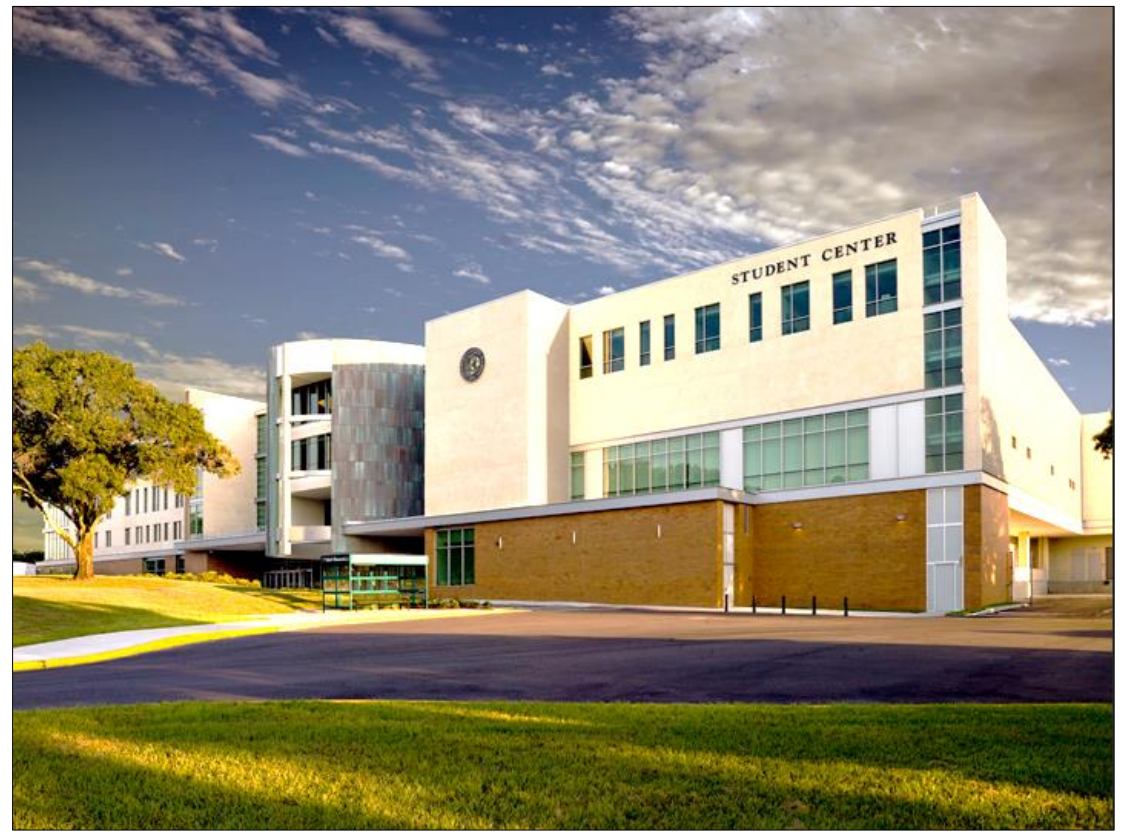

Figure 15 - USF Marshall Student Center (Source: 33)

- Route \#5 - a simple roundtrip route $(0.27$ miles $)$ inside parking lots $3 \mathrm{~A}$ and $3 \mathrm{~B}$ near the Marshall Center, as shown in Figure 16, with only right-turn behavior. This route was proposed to test the shuttle's turning capability and its capabilities in detection and reaction (slow down, stop, etc.) with respect to other vehicles or pedestrians.

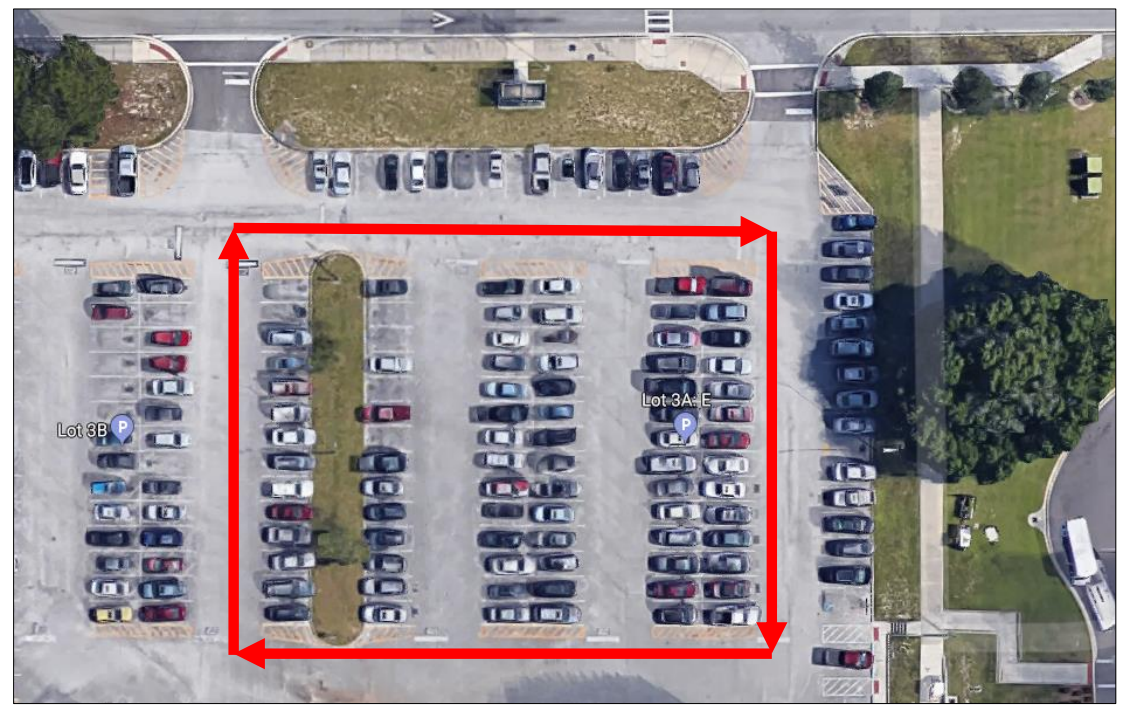

Figure 16 - Candidate Route \#5 
- Route \#6 - starts outside (0.3 miles) the Marshall Student Center, travels along Cedar Circle, proceeds to Lot 5A for a loop, and returns to Cedar Circle to the start point, as shown in Figure 17. Minor parking changes were anticipated for Lot 5A. This route was proposed to more comprehensively test the shuttle's capabilities regarding turning, speed control, and communications, detection, and reaction with other vehicles and pedestrians.

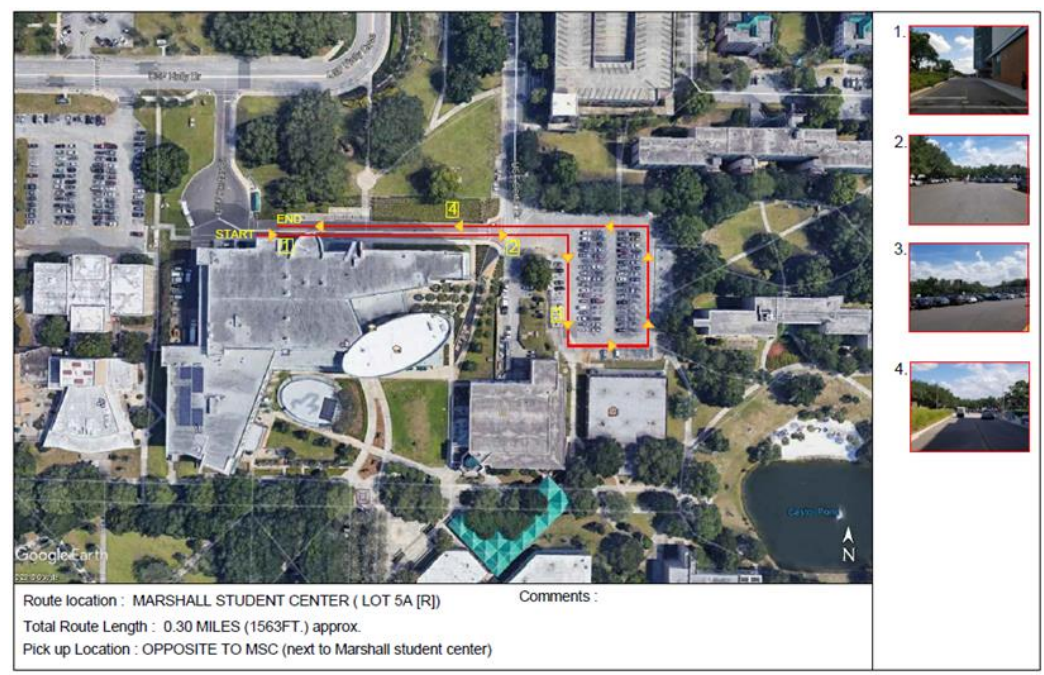

Figure 17 - Candidate Route \#6

\section{USF Research and Innovation Campus}

The USF Research and Innovation Campus is located southwest of the Library and was selected as a contingency (backup) shuttle route option.

- Route \#7 - a simple roundtrip route (0.3 miles) in the parking lot of the USF Research \& Innovation Campus beginning and ending at the visitor parking spots adjacent to USF Alumni Drive, as shown in Figure 18. No parking changes were anticipated for Route 7.

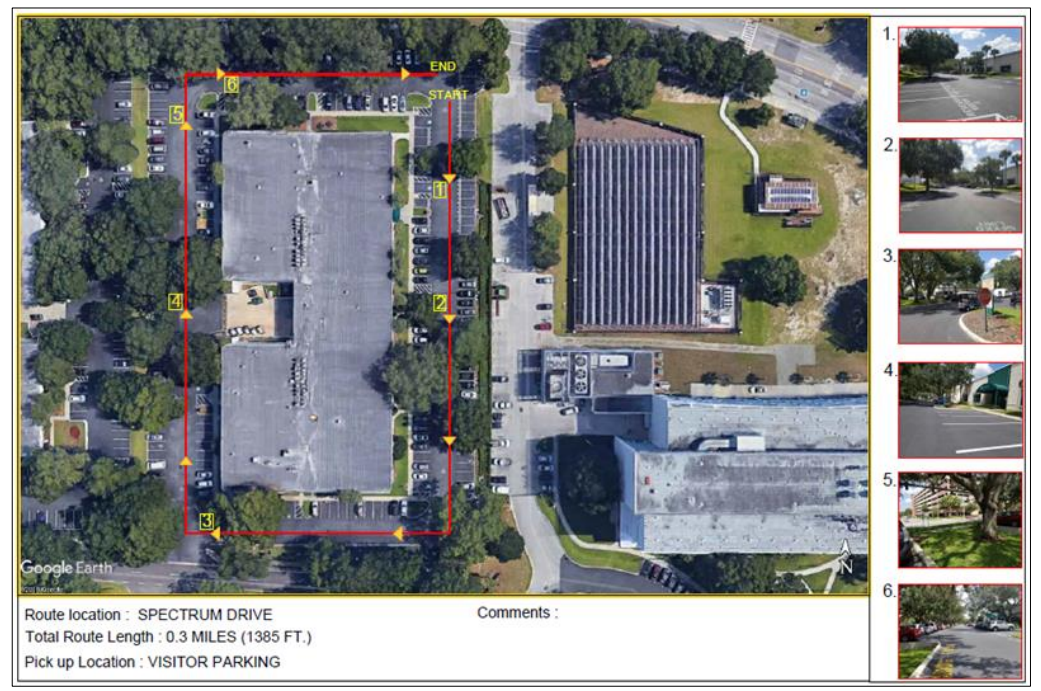

Figure 18 - Candidate Route \#7 


\section{Development of Assessment Methods for Automated Shuttle Demonstration}

Assessment methods were developed to evaluate the performance of the automated shuttle during the demonstration period. As identified during the project scope, the CUTR team used multi-dimensional assessment methods that included 1) on-board opinion/feedback survey from riders of the automated shuttle, 2) field observation of interactions among the automated shuttle, passengers, and road users, and 3) campus AV expert assessment of automated shuttle operations and recommendations for future enhancement and deployment.

\subsection{Onboard Opinion/Feedback Survey of Automated Shuttle Riders}

A paper-based stated preference survey was administered to elicit respondent opinions on participant rides on the automated shuttle. The survey inquired about respondent interests in AV technology, their exposure to AVs, their experience riding the automated shuttle, their opinions on the use of automated shuttles on campus, and trust in AVs; it also collected information on respondent demographics, current travel characteristics, crash history, and opinions on new technology adoption. The survey questionnaire was provided to each respondent before he/she embarked on an AV ride, and response sheets were collected after completing the survey. Survey data were later entered into SPSS for descriptive data analysis. The results of this exercise are discussed in Section 7.1. The survey questionnaire is provided in the Appendix.

\subsection{Field Observation Survey}

The field observation survey involved a thorough examination of interactions between the automated shuttle, passengers, and road users to gauge the performance of each during the demonstration period. Several scenarios were created and are described in Findings, Section 7.2. The field observation study is attached as an Appendix.

\subsection{Expert Opinion Survey for Automated Shuttle Performance}

A group of campus AV experts was assembled, and their opinions were sought on the performance of the automated shuttle from operational and technological standpoints. The results are described in Section 7.3. 


\section{Automated Shuttle Demonstration}

The CUTR project team sought the requisite approvals from USF stakeholders, the USF Institutional Review Board (IRB), and COAST before proceeding with the proposed demonstration. The demonstration period was scheduled for one week, February 11-15, 2019. The final route selected for the one-week demonstration was the walkway between the USF Library and the Campus Recreation Center (Candidate Route \#4), as shown in Figure 19. This was based on the top priority of safety and the opportunity to test the readiness of the AV technology for interacting frequently with passengers and road users (pedestrians, bicyclists, skateboarders) in addition to testing its capabilities regarding speed control and detection.

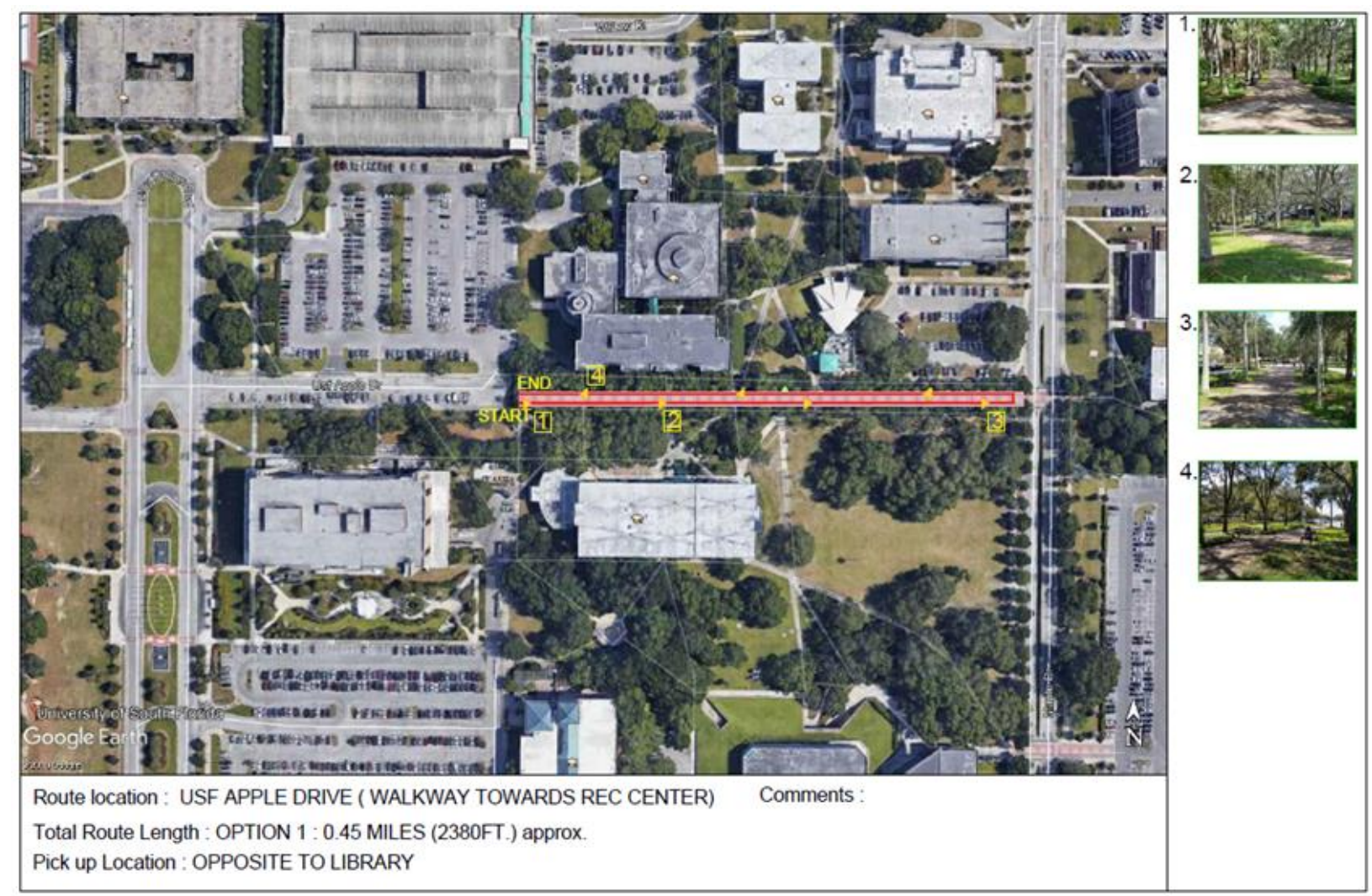

Figure 19 - Selected route for automated shuttle demonstration

Marketing efforts were conducted across the USF Tampa campus to inform students, faculty, and staff regarding the automated shuttle demonstration by disseminating flyers and posters, as shown in Figure 20, through web platforms and bulletin boards. The research team also shared details of the week-long demonstration with transportation groups in the Tampa Bay region and across Florida.

COAST and the project team conducted initial tests before the first demonstration date. After consultation with COAST, it determined that the duration of the demonstration would be 9:00 AM-1:00 PM and 2:00-5:00 PM on Monday through Friday, February 11-15, 2019. It was 
also determined that the demonstration would not take place during inclement weather such as heavy rain to allow for the safe and smooth operation of the shuttle.

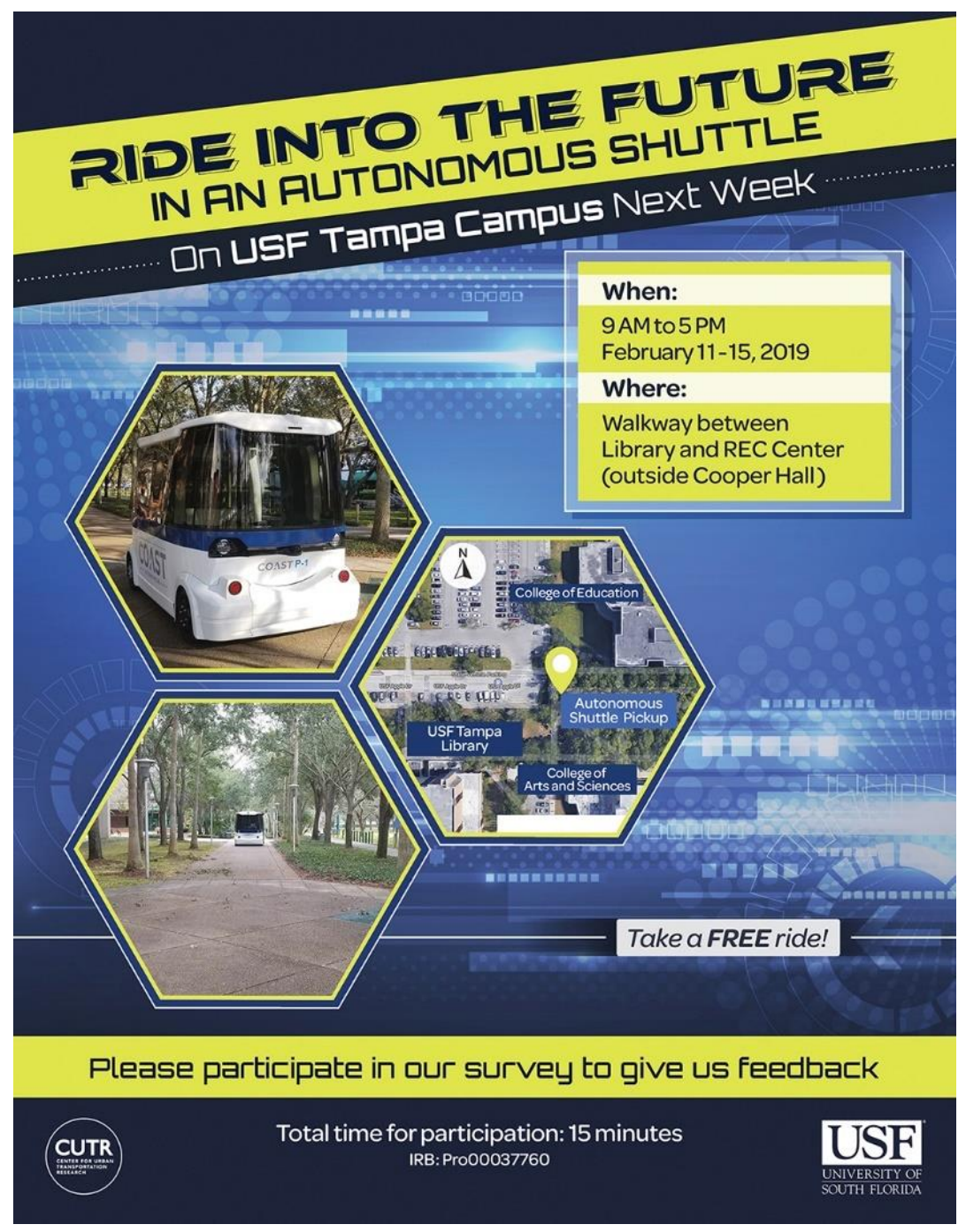

Figure 20 - Promotional flyer for campus automated shuttle demonstration

More than 500 users rode the automated shuttle during the demonstration period. Upon arrival at the demonstration site, users signed waiver documents and proceeded to the automated shuttle with a paper copy of the on-board survey. Once the ride was completed, users recorded their observations of the ride using the survey and returned it to the project team. 


\section{Research Findings}

Upon completion of the week-long demonstration, the project team analyzed the results of the survey, among other assessment methods, to evaluate the performance of the campus automated shuttle demonstration. The on-board survey was administered to every rider of the automated shuttle, and responses were sought on various aspects of the automated shuttle including but not limited to ride experience, likelihood of future adoption, willingness to pay for such a service, trust in the automated shuttle, and concerns. In total, 522 riders responded to the survey. The descriptive statistics presented in this section do not include riders who did not respond to a particular question on the survey, thereby reducing the final tally of clean responses in certain areas.

Field observations were conducted on the interactions between the automated shuttle, passengers, and road users (pedestrians, bicyclists, skateboarders). In all, more than 169 observations were recorded during the week. AV experts rode the shuttle and provided their opinions on the performance and operations of the automated shuttle, as described later in this section.

\subsection{Onboard Opinion/Feedback Survey of Automated Shuttle Riders}

\section{Respondent Demographics}

\section{Gender}

Survey results revealed that a slightly higher share of males participated and rode the automated shuttle than females, as shown in Figure 21. It is worth noting, however, that a significant share of respondents (16\% of 522) did not reveal their gender in the survey, thus resulting in a clean final sample size of 438 respondents.

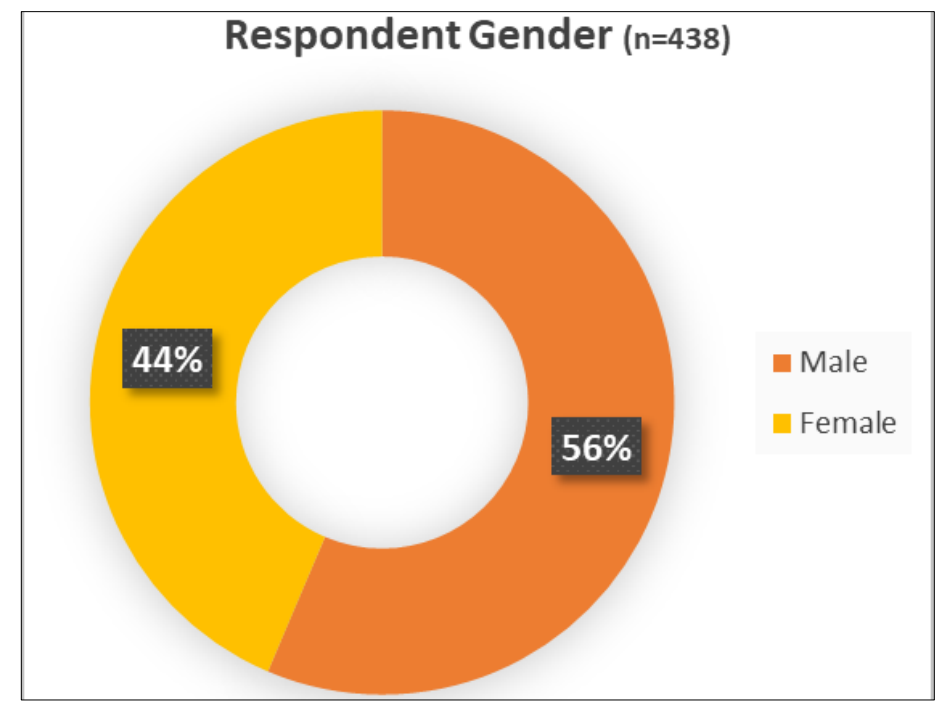

Figure 21 - Respondent gender 
Age

As the automated shuttle demonstration was held in a campus environment, a significant share of respondents $(\sim 60 \%$ of 487$)$ were age 24 or younger; respondents age 55 or older constituted only about $4 \%$, as shown in Figure 22. It should be noted that campus environments are fertile ground for testing public sentiment related to new and emerging technologies, as a significant portion of campus demographics is likely to be the main users. As such, survey results may not be representative of national trends but are useful predictors in understanding the potential market penetration of such technologies and their eventual assimilation into the market.

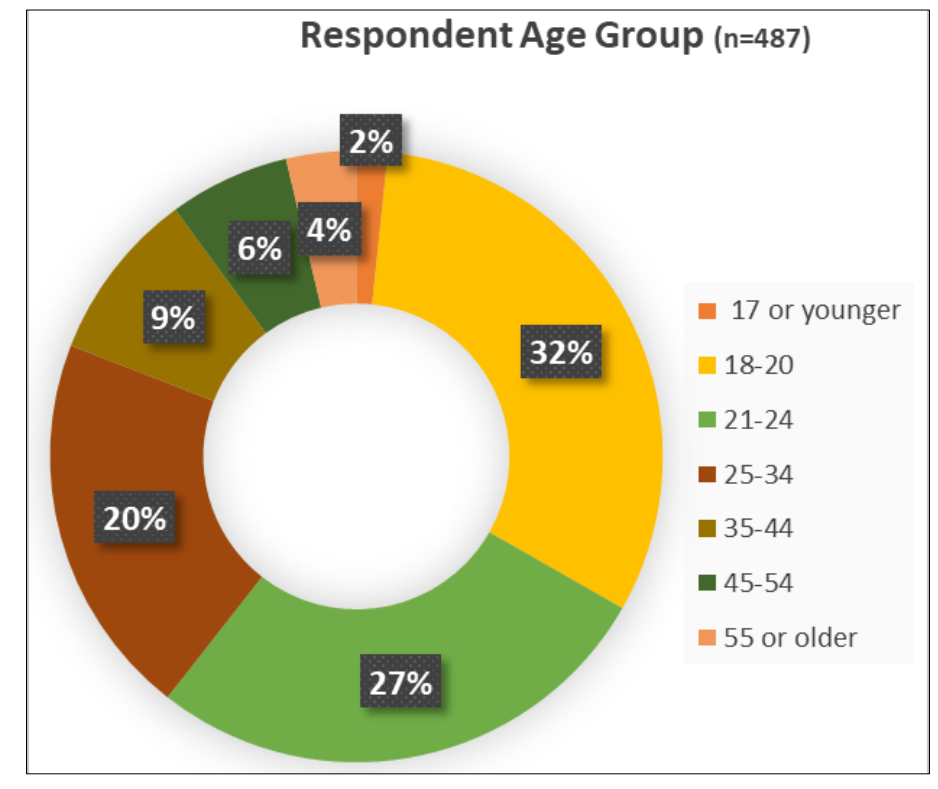

Figure 22 - Respondent age

\section{Annual Household Income}

Respondent annual household income is shown in Figure 23. Almost half of respondents belonged to households with an annual household income less than $\$ 25,000$, as expected in a campus environment in which the majority of students work only part-time. On the other hand, almost one-fifth of respondents belonged to households with an annual income in excess of $\$ 100,000$. 


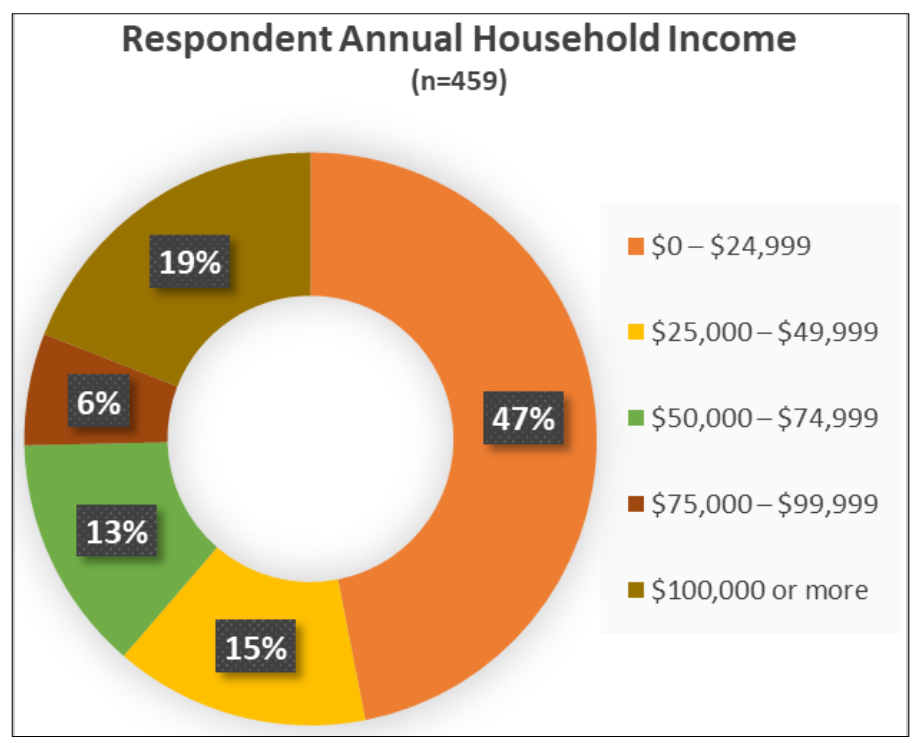

Figure 23 - Respondent annual household income

\section{Ethnicity and Race}

Respondent ethnicity and respondent race are shown in Figure 24 and Figure 25, respectively. More than $80 \%$ of respondents identified themselves ethnically as Non-Hispanic or Non-Latino. Analysis of respondent racial information revealed that a majority of riders were White (51\%), with a significant proportion identifying as African American (13\%) and Asian (26\%).

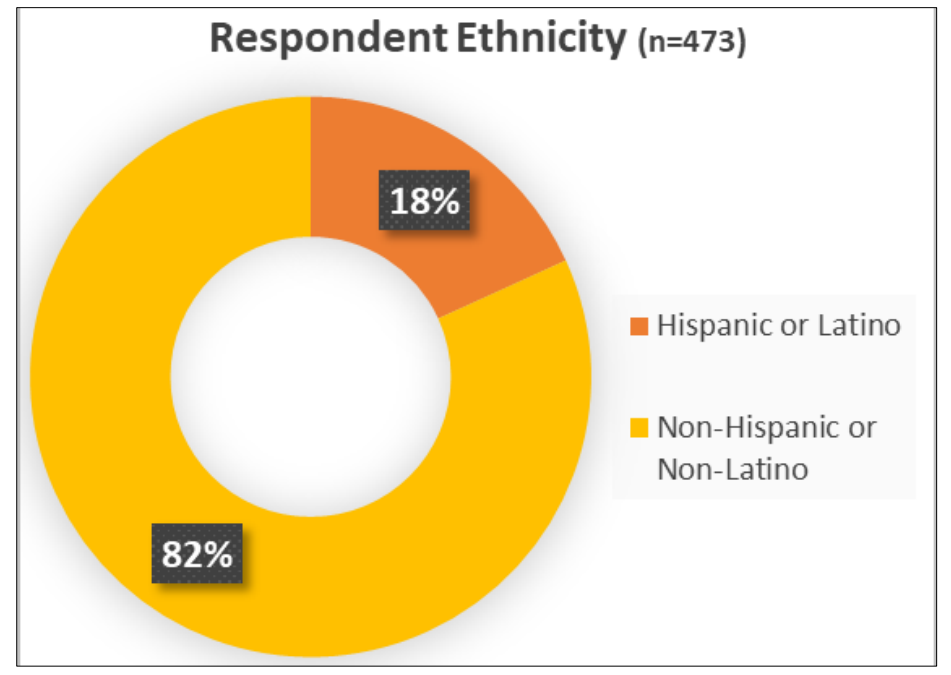

Figure 24-Respondent ethnicity 


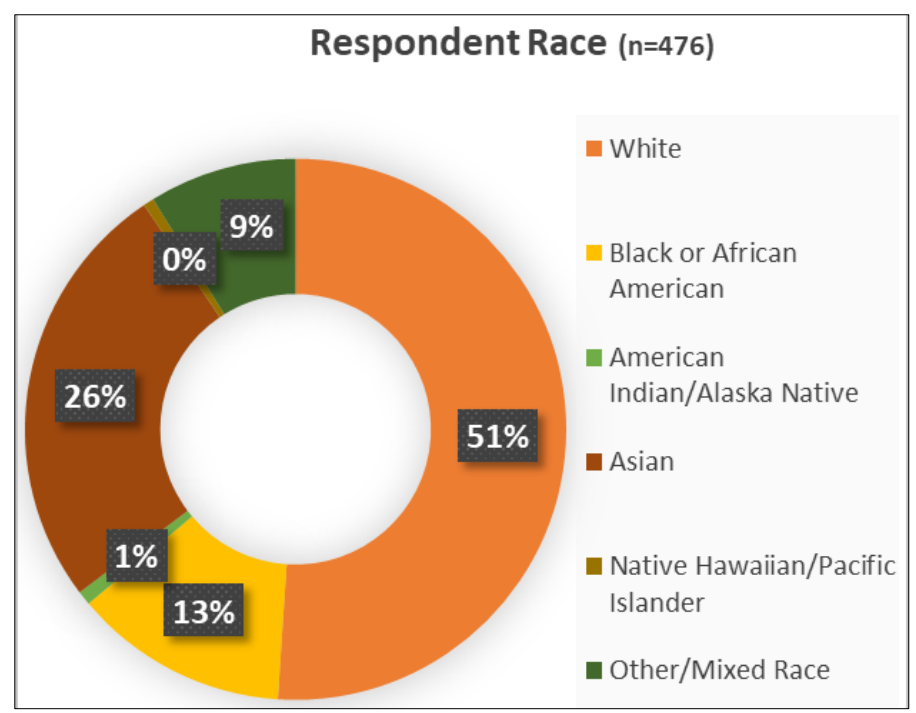

Figure 25 - Respondent race

\section{Household Vehicles}

The presence or absence of household vehicles was seen as a significant predictor in respondent opinions and preferences for new and emerging vehicles. Past studies have revealed that multivehicle households have preferences over single-vehicle households towards the use of emerging vehicle technologies. Respondent household vehicle distribution is shown in Figure 26. Results revealed that close to one-fifth of respondent households did not own a vehicle and that $75 \%$ of respondent households had two or less vehicles.

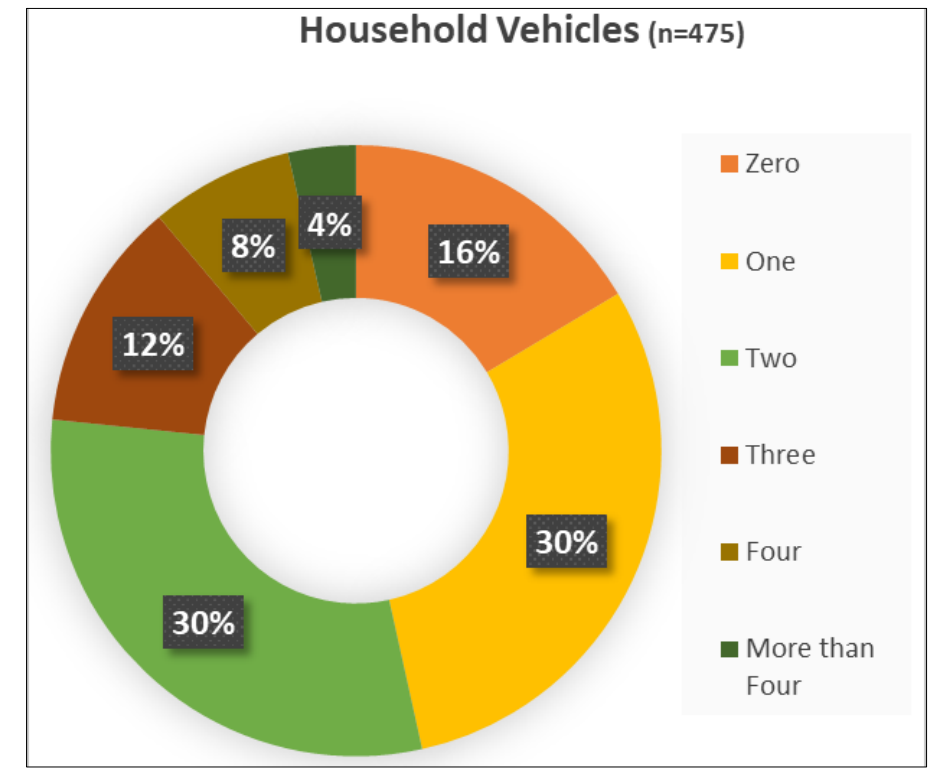

Figure 26 - Respondent household vehicle distribution 


\section{USF Status}

An important aspect of understanding public opinion of new and emerging transportation technologies is understanding the dynamics of the respondent base. Respondent status at USF was selected as an indicator to determine the exact composition of the automated shuttle riders. These respondent categories could later be used to assess more in-depth trends and conduct more sophisticated analyses into understanding opinions and preferences. Respondent status at USF is shown in Figure 27. Results revealed a significant presence of students as survey respondents. Staff and faculty comprised nearly $13 \%$ of all respondents, and $12 \%$ of riders were visitors to the campus, including many transportation stakeholders.

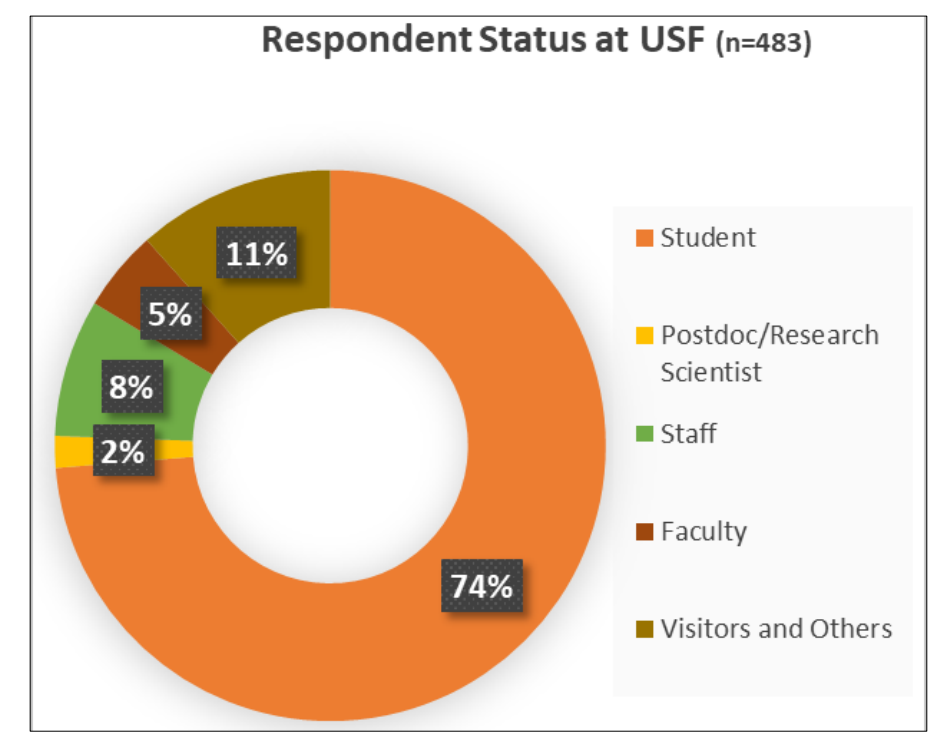

Figure 27 - Respondent status at USF

\section{Current Travel Characteristics}

Information on respondent current travel characteristics can be an important predictor in understanding public opinions and preferences for using automated shuttles when they become available in the future. As such, information regarding respondent current travel characteristics was sought by the research team. The results from this effort are outlined in this subsection.

\section{Mode of Travel}

As shown in Figure 28, survey results revealed that the majority of respondents drove alone to USF. This is not surprising, as USF has a large share of students living off-campus. Walk (17\%), shared ride $(12 \%)$, and campus shuttle $(8 \%)$ were among the survey response travel modes. 


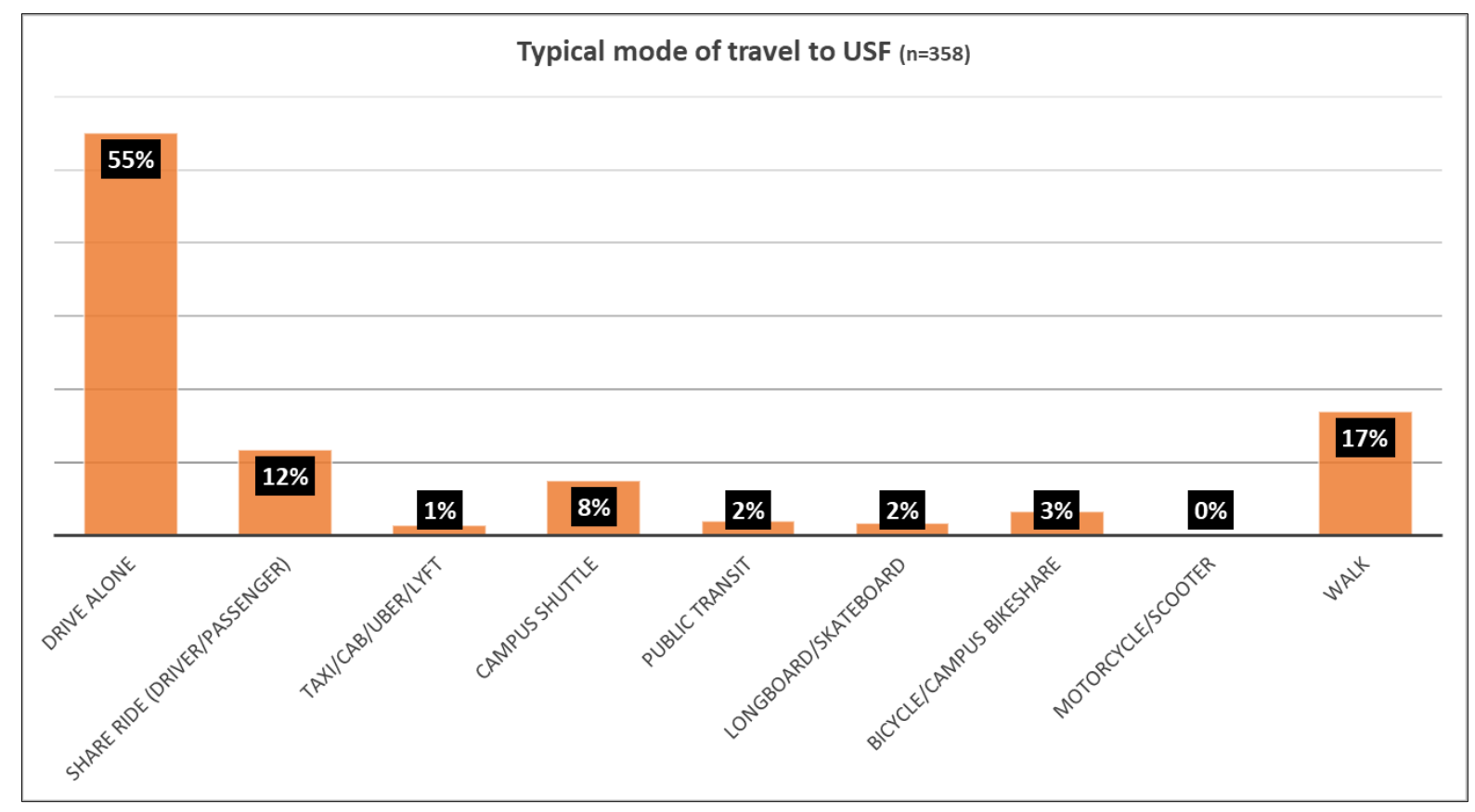

Figure 28 - Respondent typical travel mode to USF

\section{One-way Travel Distance}

Respondents were asked about their one-way travel distance to campus. As shown in Figure 29, about half traveled five miles to the USF campus, and more than one-fourth traveled 15 miles or more to the campus.

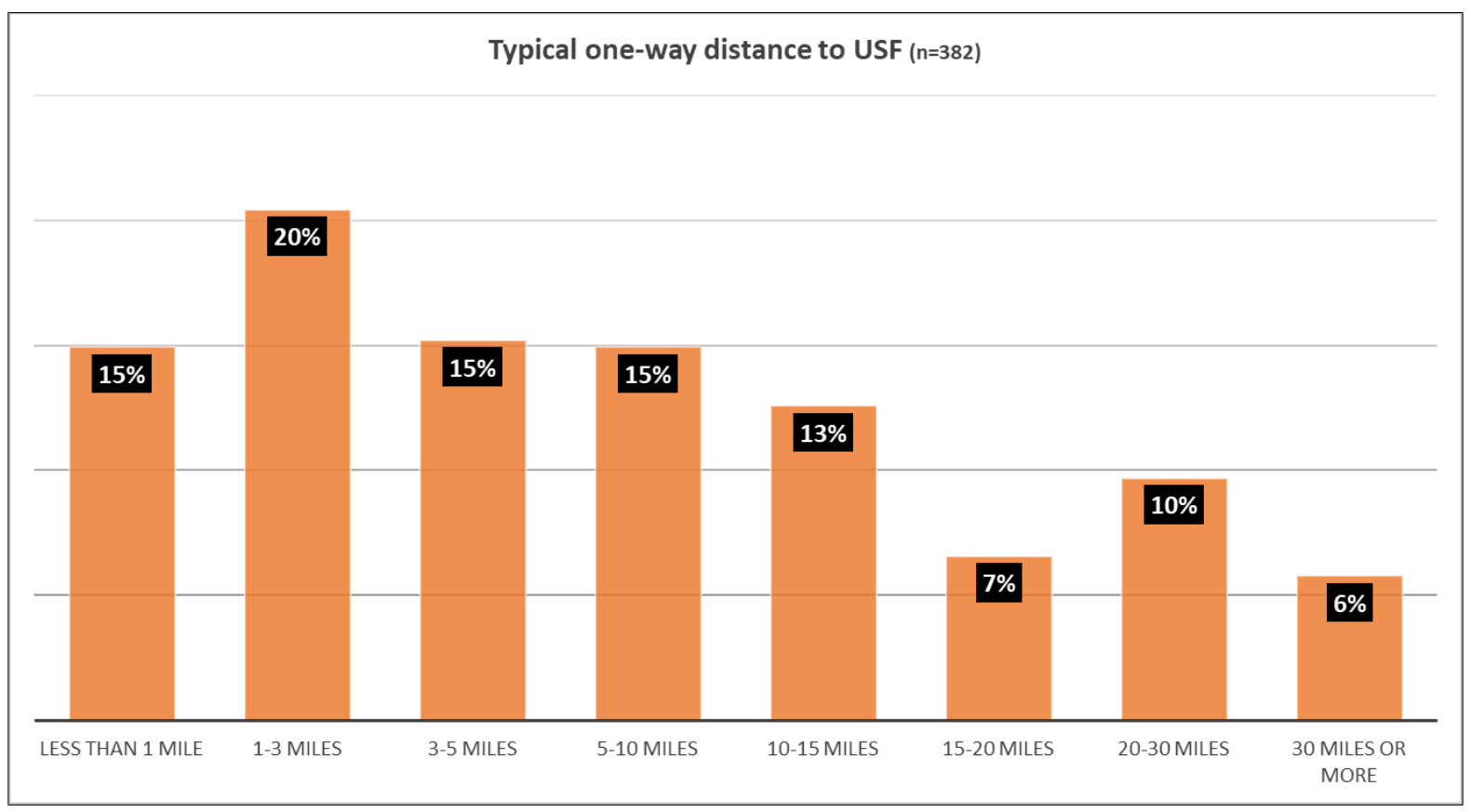

Figure 29 - Respondent typical one-way travel time to USF 


\section{One-way Travel Time}

As shown in Figure 30, more than one-fourth of respondents reported traveling 30 minutes or more one-way for their commute to USF, indicating the rather sprawled nature of respondent household locations. These findings corroborate earlier findings regarding extremely low shares of public transit/bike trips taken by USF students, faculty, and staff.

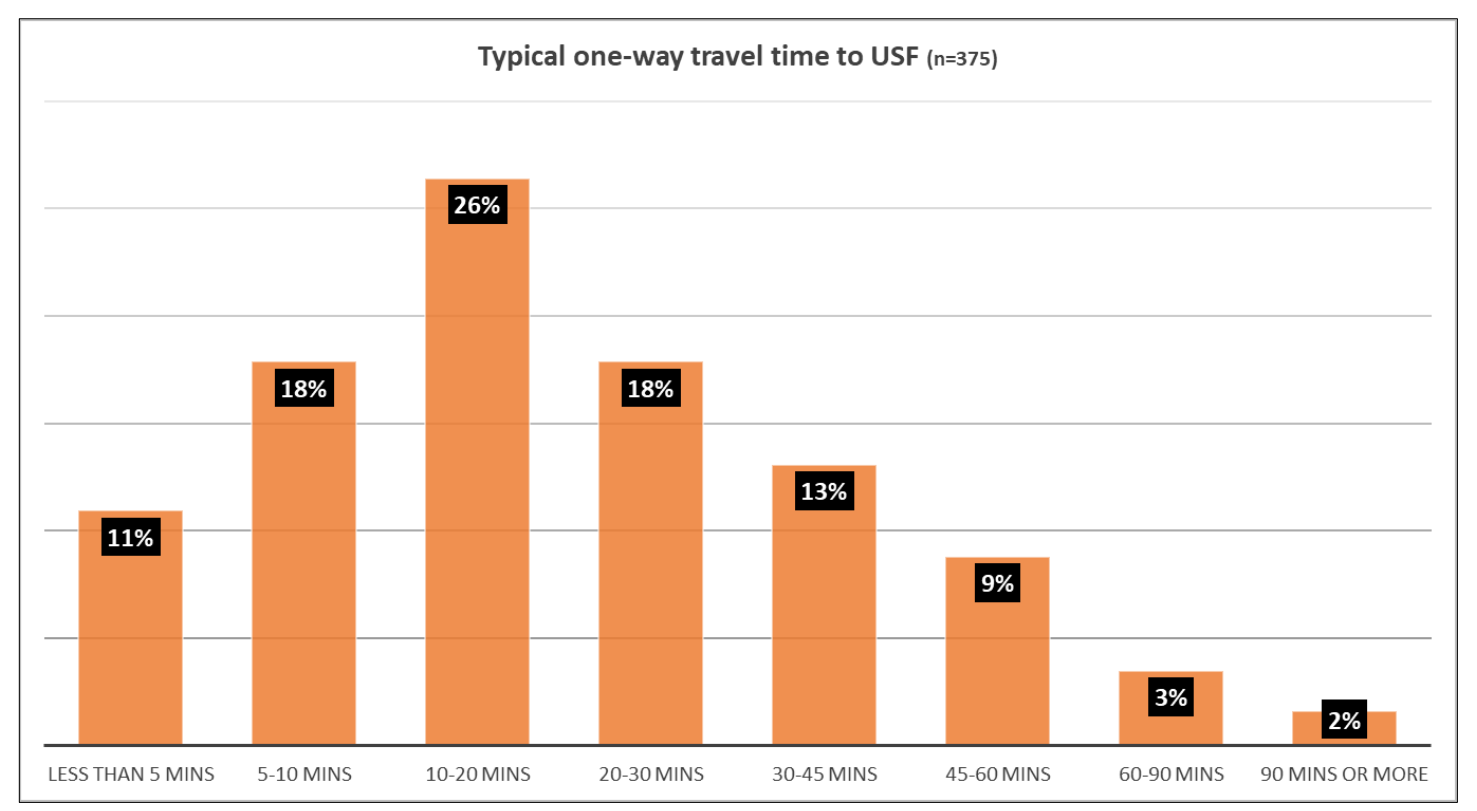

Figure 30 - Respondent typical one-way travel time to USF

\section{Crash Involvement}

Crash involvement has been found to be an important determinant in respondent preferences for new and emerging transportation technologies that remove the process of driving. As shown in Figure 31, two-thirds of respondents had not been involved in a crash in the past three years.

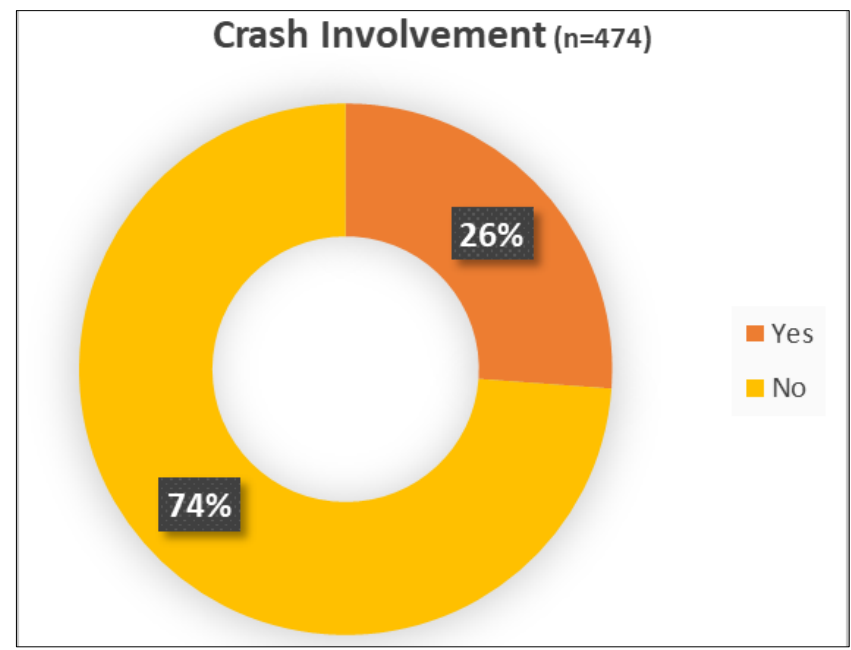

Figure 31 - Respondent crash involvement 


\section{Opinions on New Technology Adoption}

The survey inquired about respondent propensity to adopt new technologies. As shown in Figure 32 , results revealed a very small share of technology skeptics $(10 \%)$, those who either adopted a new technology only when they had to or were very late in adopting a new technology into their lifestyle. Close to $60 \%$ of respondents stated that they were likely to adopt a new technology before anyone they knew, and the remainder noted being on the fence about new technology adoption, using it only when most people they knew were already using it. These results are likely to be very significant predictors towards adoption of new and emerging transportation technologies such as automated shuttles.

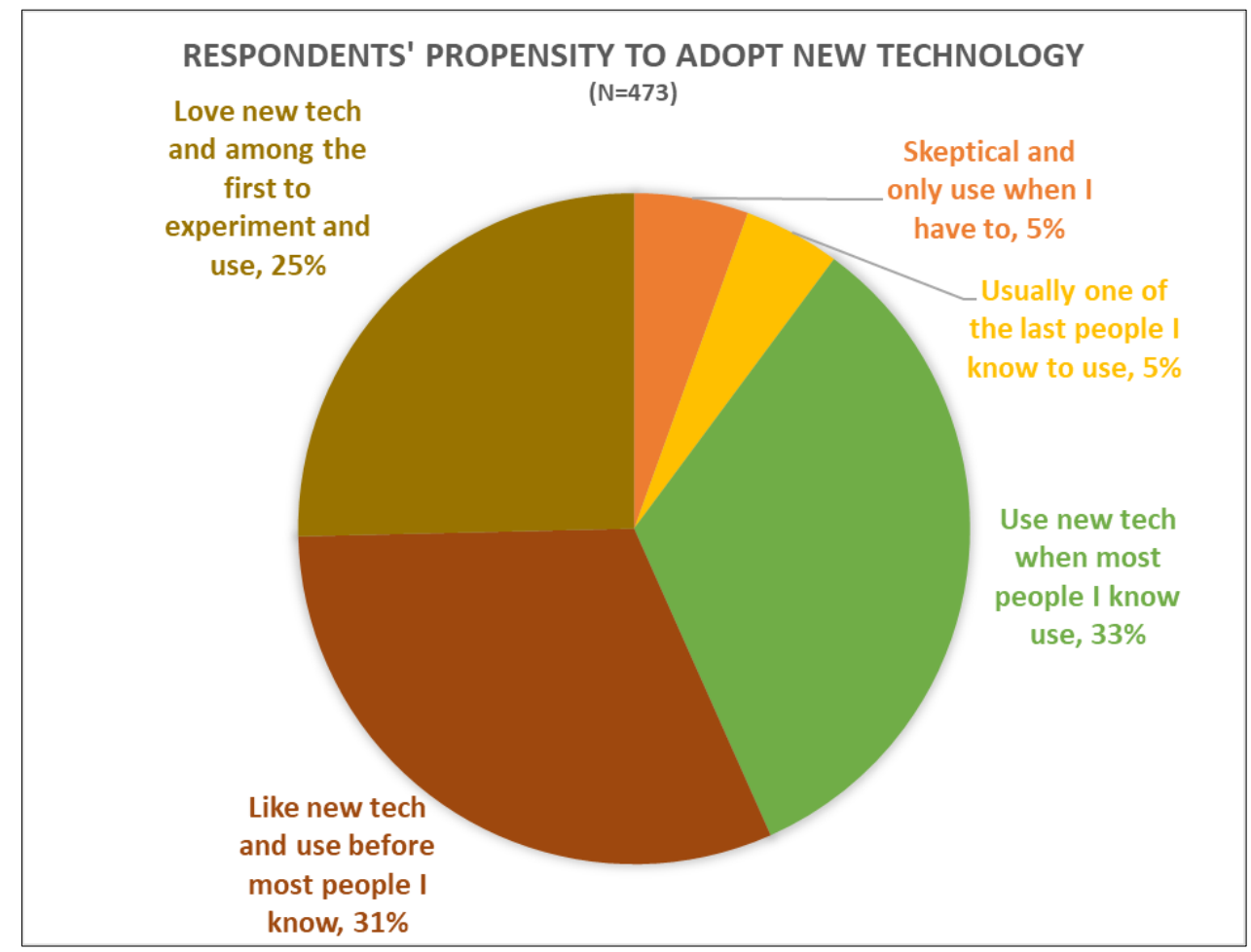

Figure 32 - Respondent propensity to adopt new technology

\section{Exposure to AVs}

Respondent opinions were elicited on their level of exposure to AVs. Past research has shown that prior exposure to technology (whether through experience or hearsay) plays an important in consumer perceptions regarding the technology. The project team sought to understand exposure using two metrics, familiarity with the technology and ride experience.

\section{Familiarity with AVs}

It is likely that some survey respondents may have been exposed to discussion or discourse regarding AVs and their future as a potential transportation offering. To elicit this exposure, respondents were asked about their level of familiarity with AVs. The level of familiarity 
followed a Likert scale, ranging from "Not at all familiar" to "Extremely familiar." Results shown in Figure 33 indicate that $26 \%$ of respondents were not at all familiar with AVs at the time of the automated shuttle ride and subsequent on-board survey. This is in line with previous findings that showed that a large majority of survey respondents typically had some exposure to AVs.

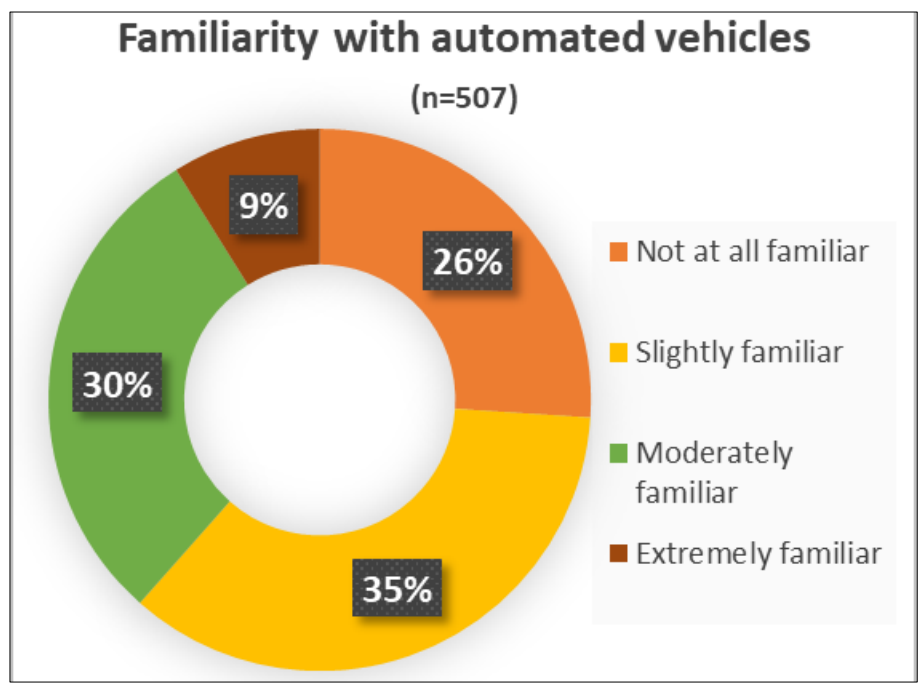

Figure 33 - Respondent familiarity with AVs

\section{Ride Experience in $A V s$}

Survey respondents were asked about their experience riding in an AV. As shown in Figure 34, a large majority (82\%) were experiencing their first ride in an AV when riding the automated shuttle. About $13 \%$ had previously ridden in an AV, potentially indicating automated people movers at airports.

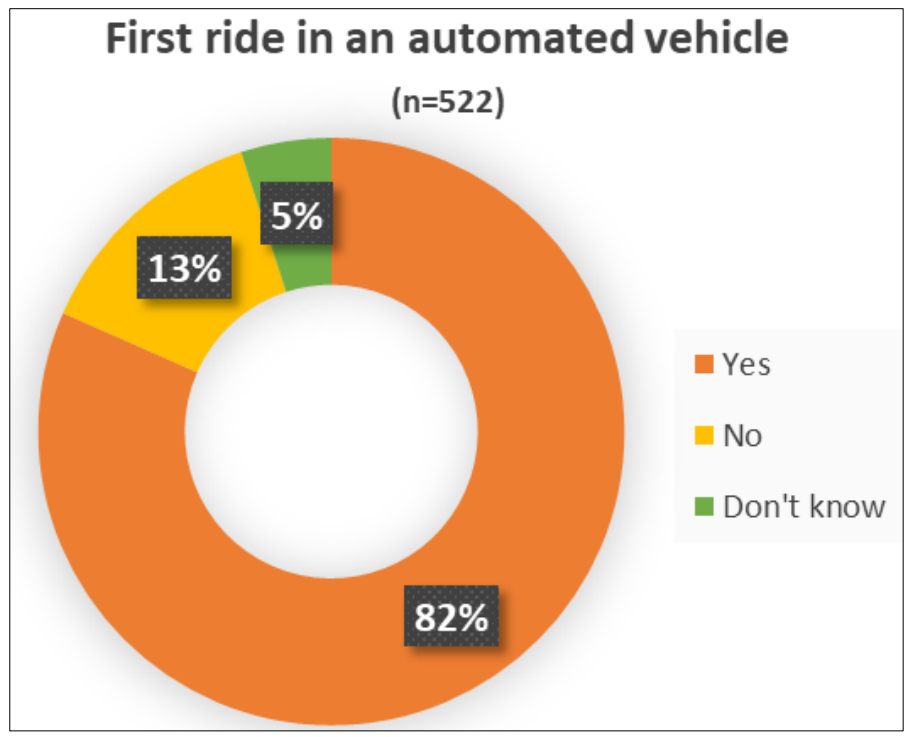

Figure 34 - Respondent first ride in $\mathrm{AV}$ 


\section{Experience Riding the Automated Shuttles}

After respondent exposure to AVs was queried, the next set of questions was aimed at understanding their experience riding the automated shuttle. Respondents were asked about their overall experience riding the automated shuttle and potential improvements on several factors pertaining to their ride.

\section{Overall Experience Riding Automated Shuttle}

As shown in Figure 35, almost three-fourths $(71 \%)$ of respondents felt comfortable riding in the automated shuttle; only $14 \%$ said they were unsure about their experience. It is likely that a small share of respondents was unable to determine their comfort level based on a single demonstration (although respondents were free to take as many rides as they liked) and would benefit from taking multiple rides in the automated shuttle.

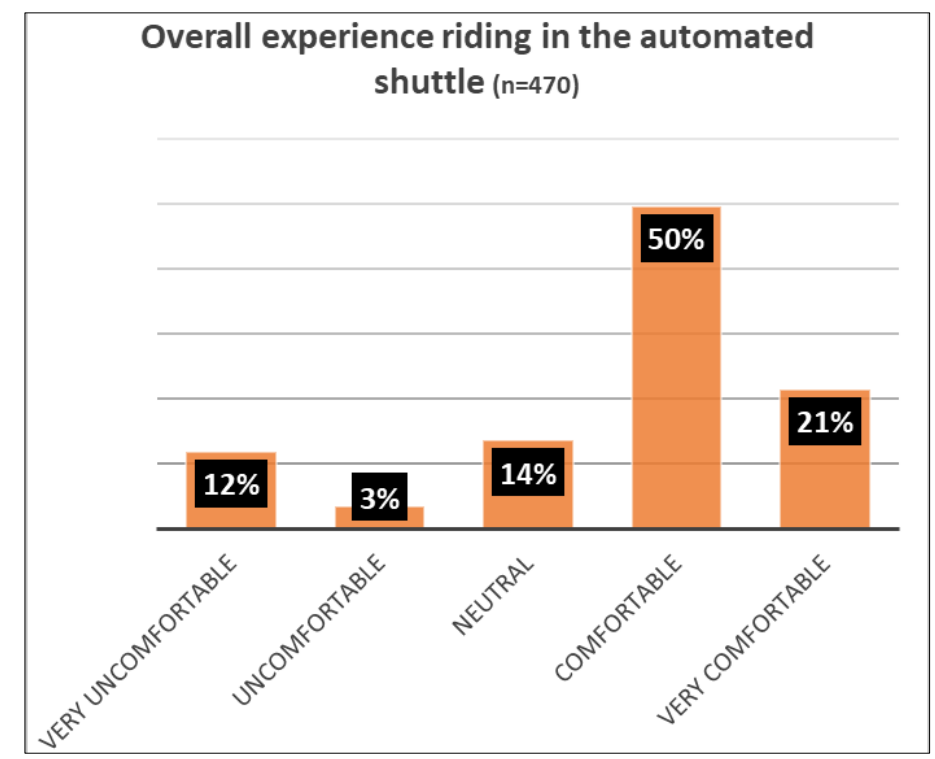

Figure 35 - Respondent overall experience riding in automated shuttle

\section{Areas for Improvement}

Automated shuttle riders were asked about improvements to various aspects of the shuttle.

Results in Figure 36 show that about half of respondents felt that the shuttle should go faster than the demonstration travel speed (4-6 mph). (Slower operating speeds were used in the campus environment in the interest of the safety and security of riders and surrounding persons; when automated shuttles become commonplace, they could travel at speeds up to $25 \mathrm{mph}$ on separated lanes or up to $15 \mathrm{mph}$ in mixed traffic.) Significant percentages of respondents also commented that the shuttle could benefit from better Wi-Fi (23\%) and better interaction with pedestrians/ bicyclists/other road users $(21 \%)$. 


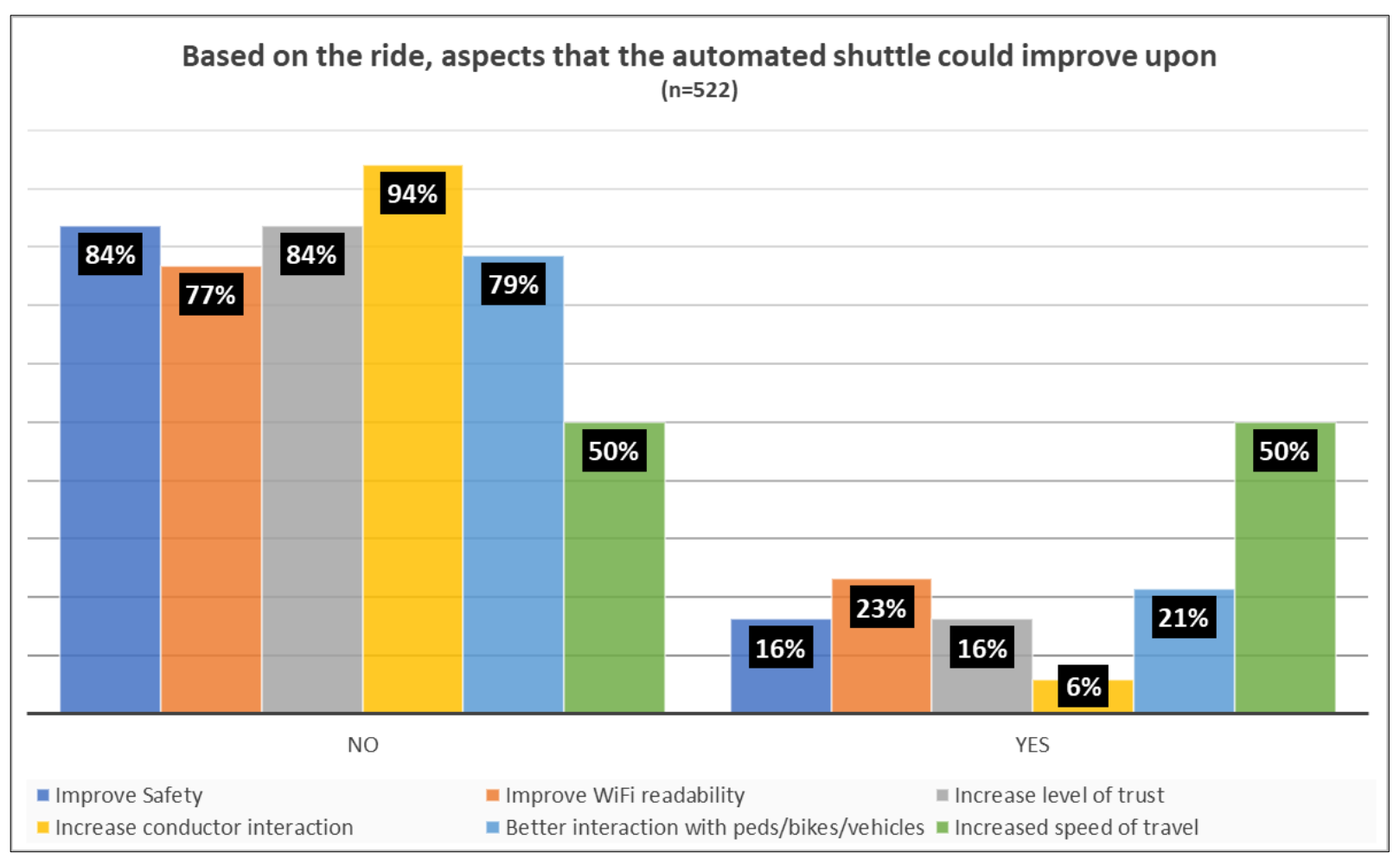

Figure 36 - Respondent opinions on automated shuttle areas to improve

\section{Using Automated Shuttles}

Respondents were asked about their likelihood to use automated shuttles if available on campus.

\section{Use of Automated Shuttles}

Respondent opinions on use of automated shuttles are shown in Figure 37 and revealed that a significant majority ( $83 \%$ ) of automated shuttle riders were comfortable with automated shuttles on large sidewalks traveling at speeds of $8-10 \mathrm{mph}$. A similar share of respondents $(82 \%)$ indicated being likely to use the automated shuttles for all campus trips. Three-fourths trusted the automated shuttle to move smoothly around pedestrians/bicyclists and other road users. More than one-third (35\%) expressed uncertainty about paying a small monthly/annual fee for using the automated shuttle, and $27 \%$ were unsure about the operation of automated shuttles without an on-board operator, indicating some safety-related concerns. 


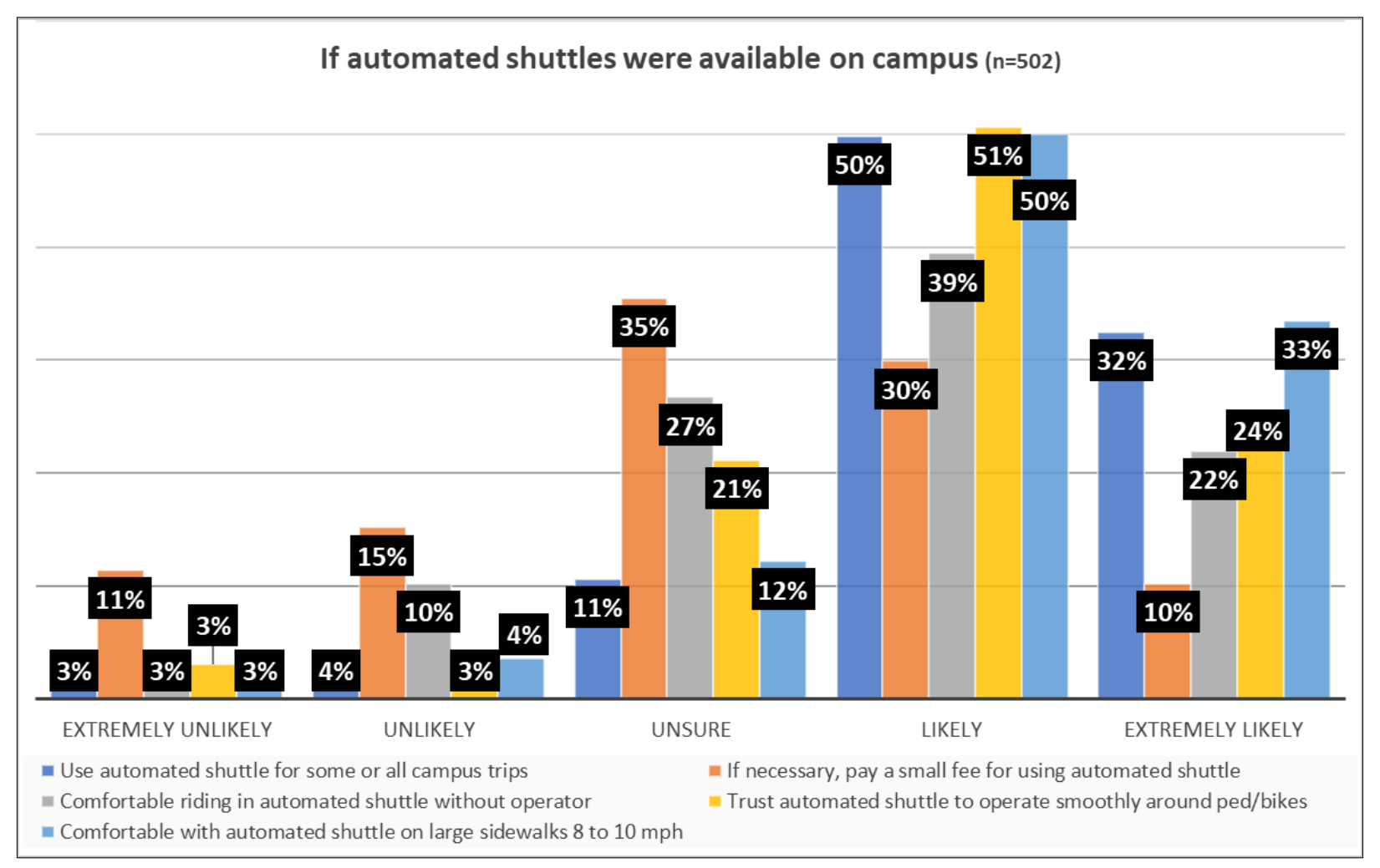

Figure 37 - Respondent opinions on use of automated shuttles

\section{Replacing Campus Trips by Automated Shuttles}

Respondents were asked if they saw potential for automated shuttles replacing trips they undertake on campus; results are shown in Figure 38 and revealed that a majority of respondents (57\%) saw the most potential in automated shuttles replacing some walk trips on campus. USF Tampa is a fairly large campus, and respondents might see the benefit of using a fleet of lowspeed automated shuttles for some longer walk trips. On the other hand, close to one-third (31\%) did not see the potential for automated shuttles replacing their personal vehicle trips on campus. 


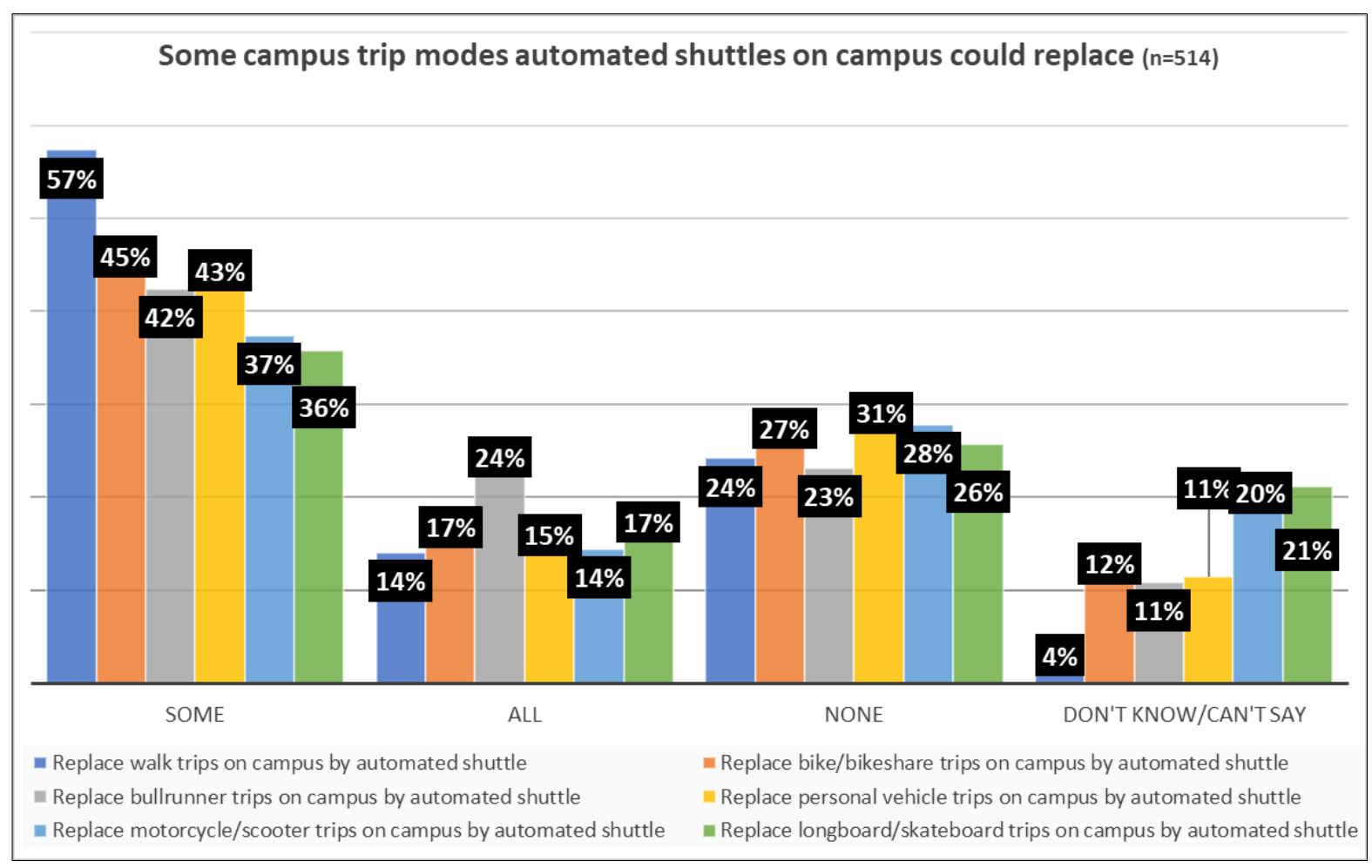

Figure 38 - Respondent opinion on replacing campus trips with automated shuttles

\section{Trust in Automated Vehicles}

Respondent trust in AVs was determined through several queries. Results as shown in Figure 39 indicate that a majority of respondents (64\%) generally would trust automated shuttles for an entire trip; only $8 \%$ said they would not trust these shuttles, and close to $29 \%$ were unsure of their opinion with regards to trust.

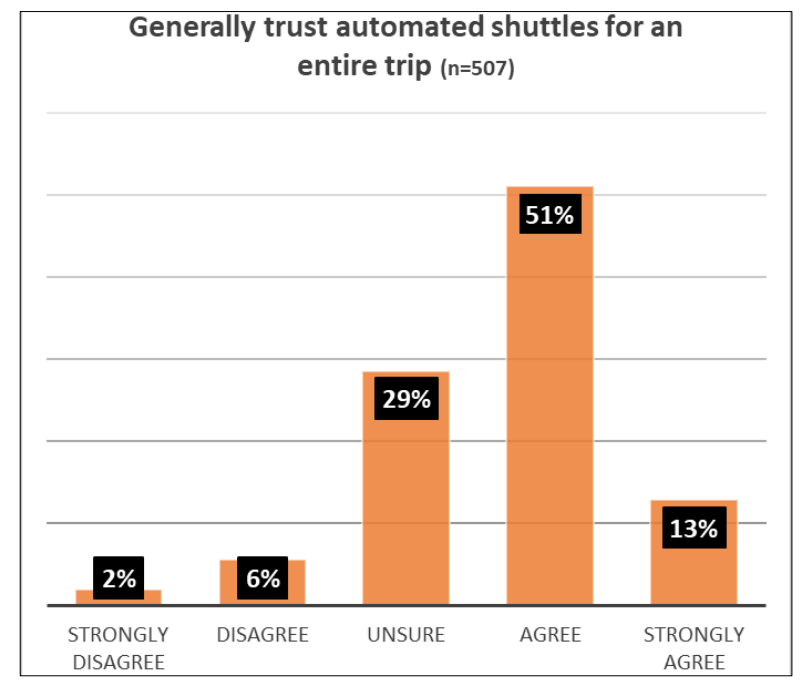

Figure 39 - Respondent trust in automated shuttles 
Respondents were asked if their trust level changed after riding the automated shuttle. As shown in Figure 40, almost half (49\%) said that their trust levels increased after riding the automated shuttle, and an almost equal share felt that the automated shuttle ride had no impact on altering their trust. The result from this demonstration provided a much-needed perspective for such exercises. Respondent trust levels with AVs likely will increase with increased exposure and demonstrations such as this on the USF Tampa campus.

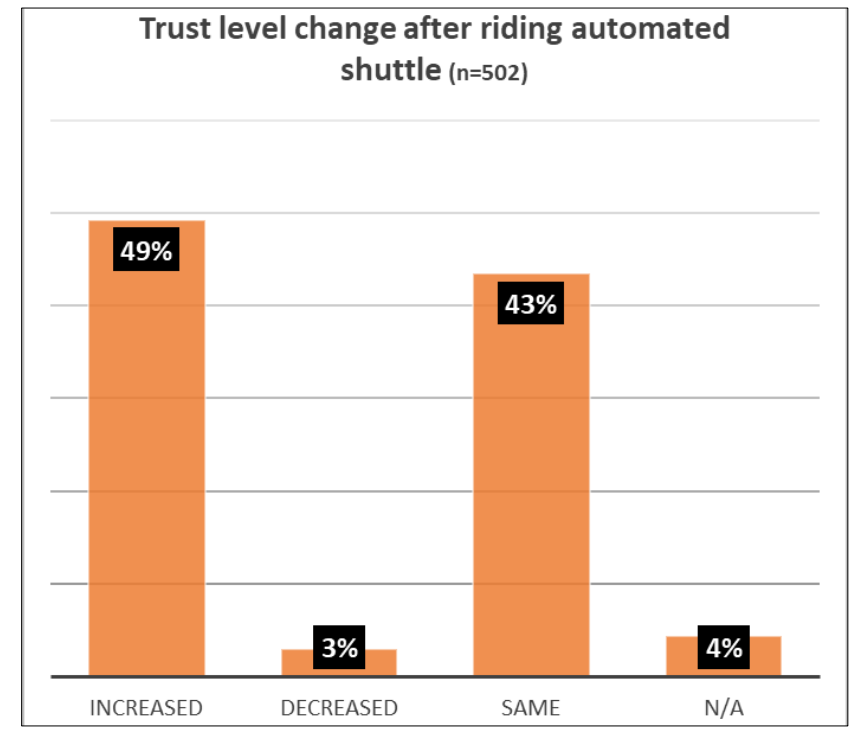

Figure 40 - Respondent change in trust after riding automated shuttle

\section{Concerns about Automated Shuttles}

Respondents were asked to provide information on factors of most and least concern about automated shuttles. As shown in Figure 41, results indicated that travel time (43\%) and safety (36\%) were the most concerning factors with automated shuttles in this low-speed environment. The low-speed nature of AVs perhaps caused some concern among some respondents who may prefer to use higher-speed modes.

It is worth noting that these results might be a factor in the demonstrative nature of this project, in which the shuttles operated at speeds of 4-6 mph. When these modes are commercially available, they would operate at speeds of 15-20 mph in separate lanes and up to $12 \mathrm{mph}$ in mixed traffic. An increase in speed to these levels is likely to have an impact on some share of respondent concerns. Nevertheless, with any emerging technology, safety was a major concern among survey respondents. As shown in Figure 42, privacy was the least concerning factor among survey respondents (41\%). 


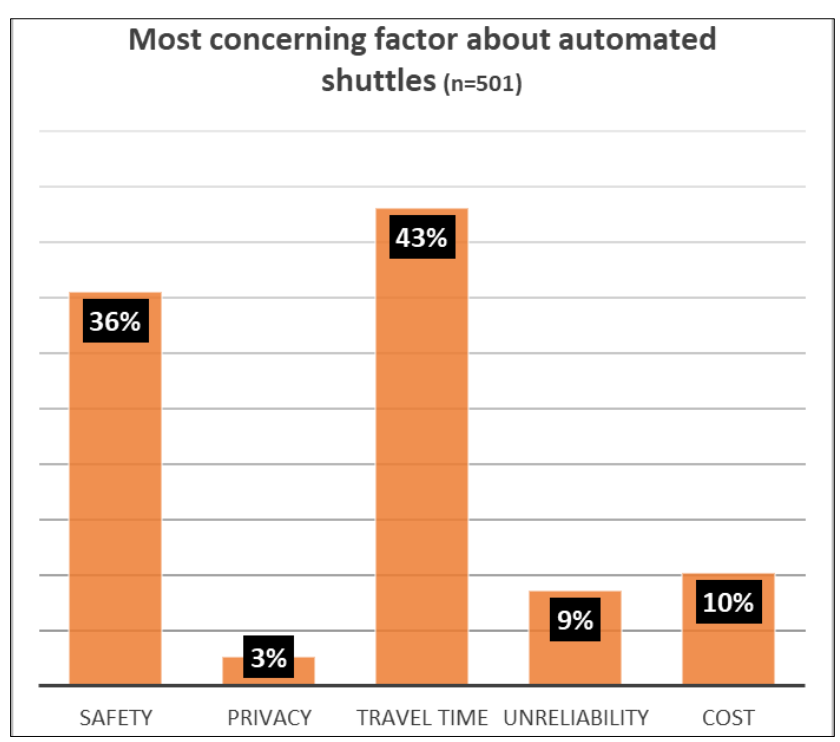

Figure 41 - Respondent most concerning factor about automated shuttles

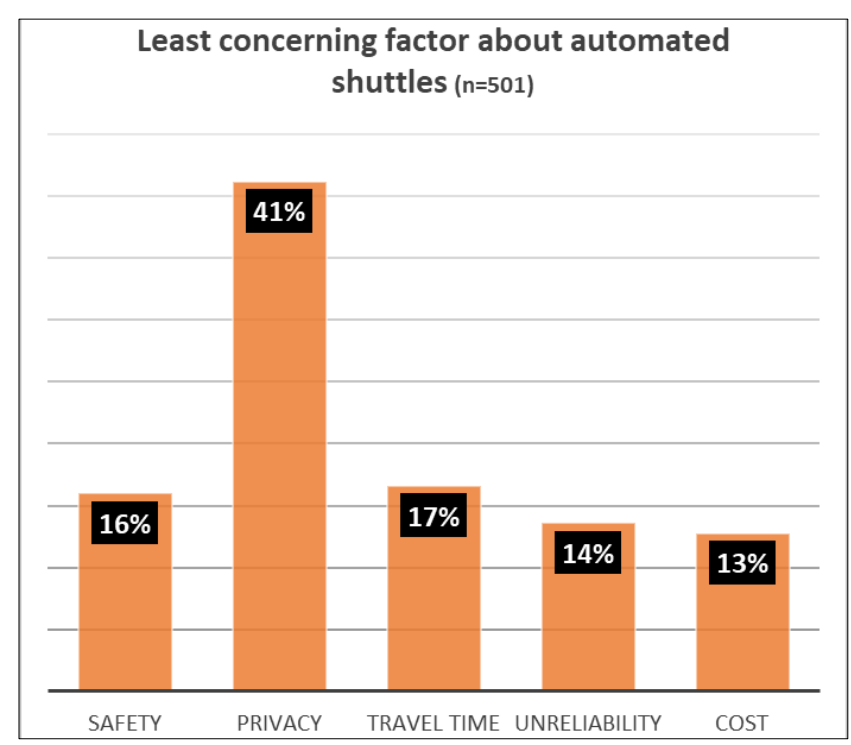

Figure 42 - Respondent least concerning factor about automated shuttles

\subsection{Field Observation Studies}

As noted, the CUTR team conducted field observation studies to evaluate the interactions between the automated shuttle and road users. Due to the nature of the demonstration, the field observation included the automated shuttle, pedestrians, bicyclists, and skateboarders. The methodology involved a systematic effort to list every possible observation that the research team could gather from the AV demonstration. Members of the project team were deployed at the site of the demonstration to observe interactions and record observations in a coded fashion. The list of field observation elements is as provided in the Appendix. The results of this exercise are as follows. 


\section{Events Observed during Field Observation}

The CUTR team identified 20 possible types of events that could take place during the weeklong demonstration. Almost half of these events (46\%) involved a pedestrian walking in the opposite direction of the automated shuttle on one side. Other major events included pedestrians walking in the same direction as the automated shuttle on one side (14\%) and pedestrians walking in the same direction as the automated shuttle in front (13\%). A complete list of the events observed is as shown in Figure 43.

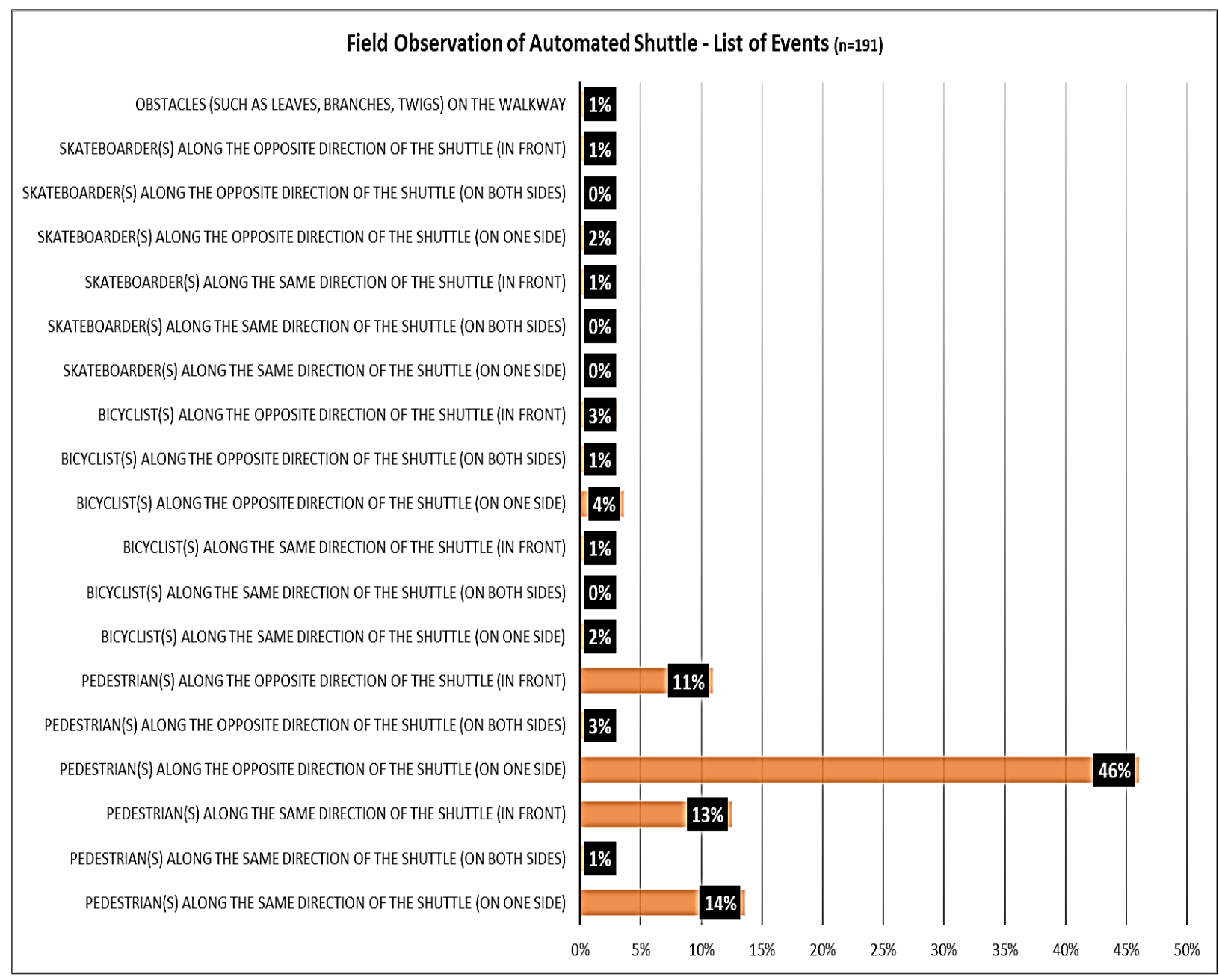

Figure 43 - Events observed during automated shuttle demonstration

\section{Automated Shuttle Reactions during Field Observation}

When faced with the prospect of interacting with its surrounding elements, the CUTR team observed that the COAST P1 automated shuttle gradually adjusted its speed and continued its trip in a safe manner for the majority of events (38\%). This displayed the potential of the lowspeed automated shuttle to safely navigate a pedestrian-dominated walkway without any major problems. Another one-fifth of the instances (19\%) involved the shuttle gradually adjusting its 
direction and continuing its trip when faced with an interaction. In other cases (3\%), the shuttle suddenly decelerated or came to a halt along its path with no apparent change in direction. This is the typical response of the automated shuttle when faced with obstacles that it felt it could not overcome. Other reactions observed are described in Figure 44.

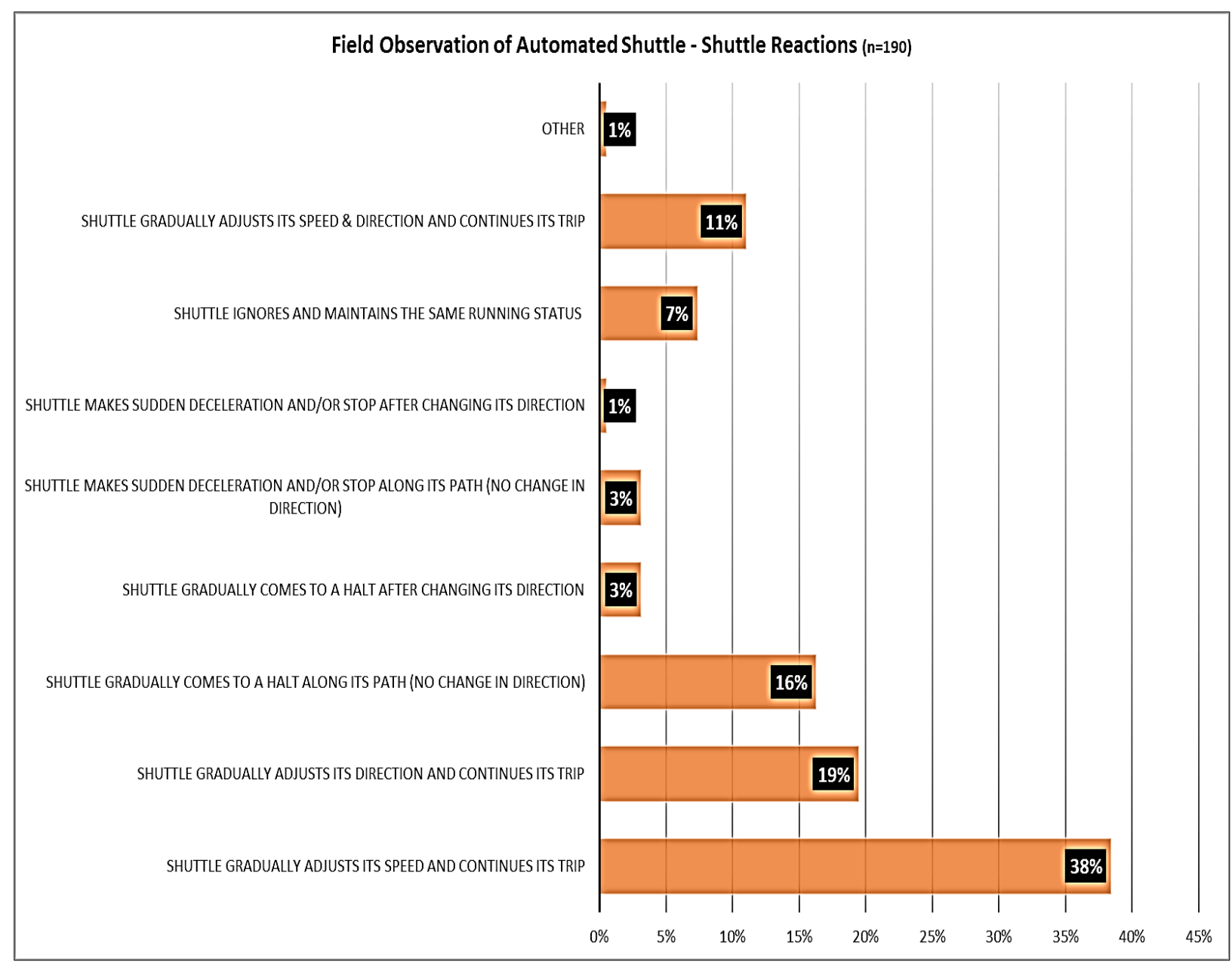

Figure 44 - Automated shuttle reactions observed during field observation

\section{Pedestrian Reactions during Field Observation}

Similar to the reactions to the automated shuttle during the field observation, it was vital to capture the interactions of road users (pedestrians, bicyclists, and skateboarders) with the automated shuttle. Results revealed that during $65 \%$ of interactions with the automated shuttle, pedestrians were aware of the movement of the automated shuttle and kept moving in the same way as before; $16 \%$ of all pedestrian interactions involved the pedestrian seemingly being unaware of the movement of the automated shuttle during the point of interaction, and 5\% involved pedestrians crossing the walkway in front of the shuttle at a relatively close distance. Other observations are described in Figure 45. 


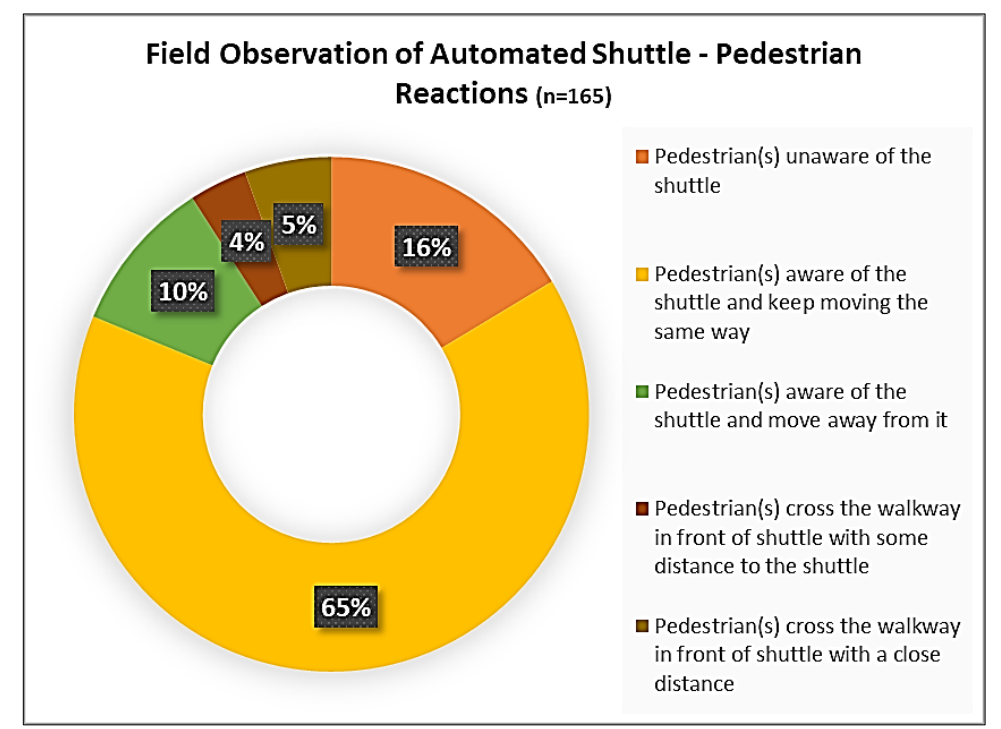

Figure 45 - Pedestrian interactions with automated shuttle

\section{Bicyclist Reactions during Field Observation}

A similar analysis of bicyclist reactions to the automated shuttle captured during field observations, as shown in Figure 46, revealed that a large share of bicyclists (74\%) noticed the automated shuttle moving and maintained their direction of navigation. This shows the relative level of confidence among bicyclists to trust the automated shuttle. A smaller share of bicyclists (11\%) moved away from the path of the automated shuttle once they made eye contact with it. Other observations are also described in Figure 46.

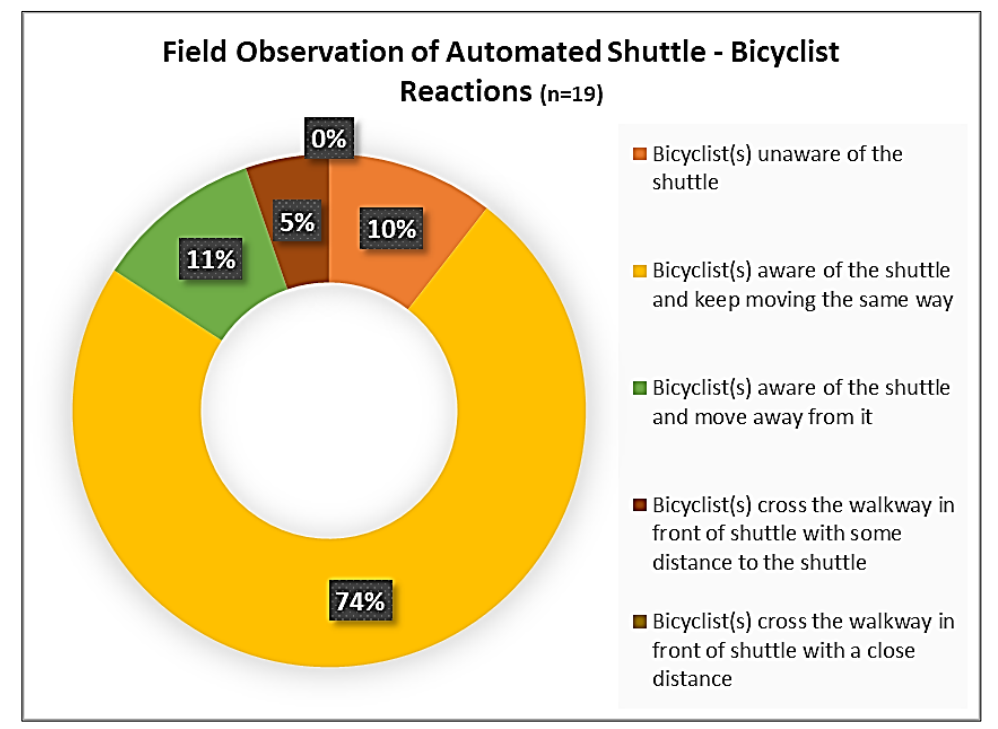

Figure 46 - Bicyclist interactions with automated shuttle 


\section{Skateboarder Reactions during Field Observation}

Skateboarders can present a challenge to the trajectory of the automated shuttle because of their relatively higher speeds and unpredictable directions of motion. This was identified as a major interaction to be observed by the project team. Only five such instances were observed during field observation. Results shown in Figure 47 reveal that skateboarders were aware of the automated shuttle and kept moving in the same direction during $60 \%$ of such events; the remaining $40 \%$ of interactions involved the skateboarders crossing in front of the automated shuttle at a relatively close distance. It should be noted that only five interaction instances is a small number for making generalized statements about these scenarios, but it can assist analysts in understanding potential conflicts that could arise with automated shuttle operating on skateboarder-intensive pathways.

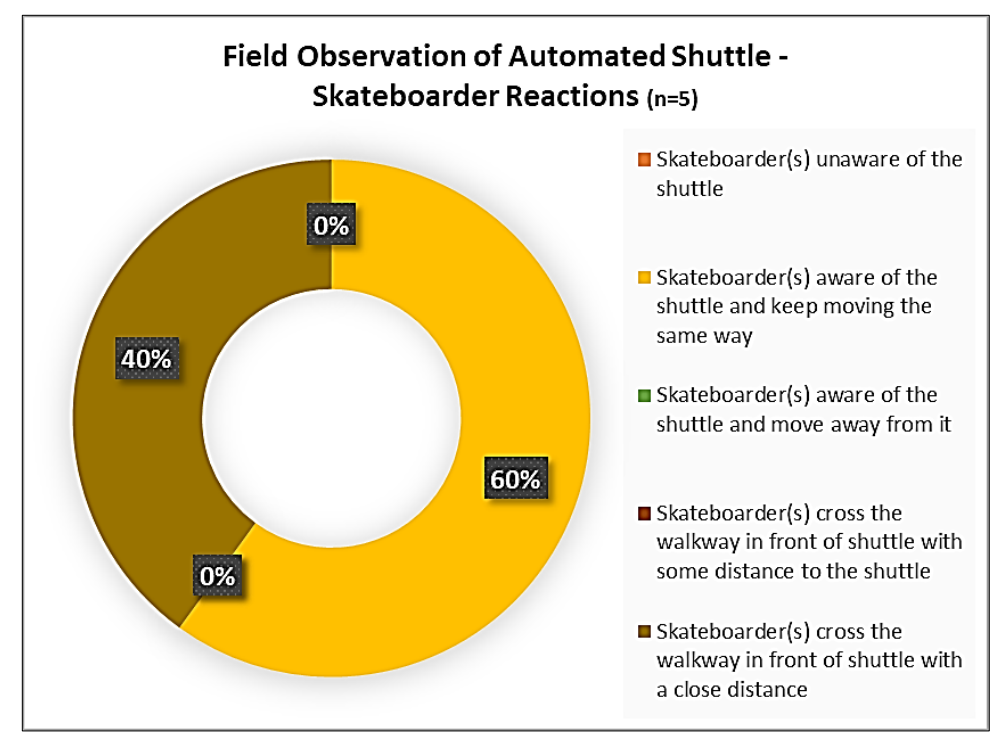

Figure 47 - Skateboarder interactions with automated shuttle

\subsection{Automated Vehicle Expert Assessment}

The CUTR team invited three connected/automated vehicle (CAV) experts from the USF campus to ride the automated shuttle and provide feedback based on their experience. These experts were asked to evaluate the effectiveness of the automated shuttle based on the following parameters:

- Ride experience and comfort during the automated shuttle ride

- Interactions between the AV shuttle and road users (and vice versa)

- Recommendations for future deployment

The summarized responses from these experts are provided in the following paragraphs. 


\section{Ride Experience and Comfort during Automated Shuttle Ride}

Overall, the experts felt that the ride was smooth and comfortable, especially during the starting and stopping motions. Braking was soft, with no abrupt motion.

The ride of the shuttle was smooth, especially in starting and stopping. The shuttle's max speed was between 3 to $5 \mathrm{mph}$. The shuttle was operating in a mixed environment with pedestrians, bicyclists, and people riding on skateboards, scooters, etc.

\section{Interactions between AV Shuttle and Other Users}

The CAV experts felt that the automated shuttle was able to navigate the path and avoid coming into direct conflict with road users. They also noted that the shuttle tended to stop for prolonged times when constant streams of pedestrians were crossing its path or going ahead of it.

The shuttle was able to navigate the path and avoided the areas where people were sitting on benches that lined the path as well as reduced speed when approaching an area where a large number of pedestrians was crossing its path. The shuttle did seem to stop for prolonged times when a constant stream of pedestrians crossed the path.

Another major observation dealt with distracted road users and the shuttle's passive approach to suitably adjust its distance and direction in order to navigate ahead.

Since the shuttle is electric, it is very quiet in operation. In a few instances, pedestrians were walking distracted (headphones, using smartphone etc.). The shuttle was traveling behind them and adjusted its speed to essentially follow them until they cleared the path for travel. Some were surprised, but most did not seem to mind.

\section{Recommendations for Future Deployment}

Overall, the experts felt that the low-speed nature of the automated shuttles made it a safe and suitable application for deployment on large campuses (such as universities, commercial campuses, hospitals, theme parks, and retirement communities). It was their belief that timed services with information on shuttle arrivals at stop locations would benefit campus communities for using this as a mode of transportation around campus. They also noted that AV technology is in its infancy, where smooth operations around intersections and with road vehicles are still some time away. Investment is required both on the AV technology and the existing transport infrastructure for ensuring smooth operations.

One note is that students on campus are used to sharing their path with golf carts, which university staff, faculty, and student organizations use frequently to travel within the non-motorized paths of the campus. For future deployments, there will 
have to be a service similar to existing shuttle services to know the schedule and track live the path and location of the shuttle for ease of use.

At this time and based on experience, the shuttle cannot navigate intersections of any kind without an operator manually driving. This is one of the major components missing so shuttles like this can overcome the boundaries of closed routes and be available to ride on the road with other vehicles. 


\section{Modeling Usage and Willingness-To-Pay}

Respondents were asked if they would use automated shuttles for some/all of their campus trips and if they would, if required, pay a small monthly annual fee to use the automated shuttle on campus. Their response categories are ordered in nature, ranging from Extremely Unlikely to Extremely Likely, and were combined into a discrete binary choice-Unlikely (Extremely Unlikely + Unlikely + Unsure) and Likely (Likely + Extremely Likely). Binary logit and probit models are two possible model specifications that can be applied to model binary choices as a function of explanatory variables.

Binary logit model specification has been widely used in transportation research (34-36). One of the assumptions in the binary logit modeling approach is that the parameters of the variables are fixed across all observations. This assumption may be incorrect in understanding factors influencing adoption and willingness to pay because of unobserved heterogeneity. To account for this, a random parameters model can be specified. Following Train (37) and others, a function that determines the probability that respondent $n$ will use the automated shuttle is defined as

$$
U_{s} e_{i n}=\boldsymbol{\beta} \boldsymbol{X}_{\text {in }}+\varepsilon_{\text {in }}
$$

where, $U_{s} e_{i n}$ is a function determining usage likelihoods, $i$ is the alternative (likely or unlikely); $X_{\text {in }}$ is a vector of explanatory variables; $\boldsymbol{\beta}$ is a vector of estimable parameters, and $\varepsilon_{\text {in }}$ is the error term. If the error terms are assumed to be generalized extreme value distributed, McFadden (38) has shown that the binary logit model is

$$
P_{n}(L)=\frac{E X P\left[\boldsymbol{\beta}_{L} \boldsymbol{X}_{L n}\right]}{\operatorname{EXP}\left[\boldsymbol{\beta}_{L} \boldsymbol{X}_{L n}\right]+E X P\left[\boldsymbol{\beta}_{U L} \boldsymbol{X}_{U L n}\right]}
$$

where, $P_{n}(L)$ is the probability respondent $n$ will likely use the automated shuttle; $\boldsymbol{X}_{L n}$ and $\boldsymbol{X}_{U L n}$ are vectors of explanatory variables that impact the decision to likely to use the automated shuttle (L) and unlikely to use the automated shuttle (UL), respectively; $\boldsymbol{\beta}_{L}$ and $\boldsymbol{\beta}_{U L}$ are corresponding vectors of estimable parameters. Without loss of generality, $\boldsymbol{\beta}_{U L} \boldsymbol{X}_{U L n}$ can be set to zero (39).

Random parameter binary logit models were estimated for both use and willingness-to-pay models (with 200 Halton draws), as documented by (40), but the resulting model estimations were not found to be statistically more significant than the fixed-parameter model estimations. To determine the effect that individual explanatory variables have on response probabilities, marginal effects are computed for each explanatory variable. The marginal effect of an explanatory variable produces the effect that a one-unit increase in an explanatory variable has on the response probabilities. Since each respondent would have his/her own marginal effect, we report the average marginal effect over all respondents. 


\subsection{Model Estimation Results}

Binary logit model estimations for use of automated shuttles and willingness to pay for automated shuttles, if needed, are presented in Tables 2 and 3, respectively.

Results shown in Table 2 reveal gender-level differences in respondents' likelihood to use automated shuttles for some/all campus trips. It appears that males were less likely to use to automated shuttles for some/all trips than their female counterparts. Additionally, respondents who identified themselves ethnically as White and those who belonged to low-income households (annual income $<\$ 50,000$ ) were less likely to use automated shuttles for some/all of their campus trips. It is possible that respondents from low-income households have cost-related concerns when it comes to using new/emerging transportation technologies. On the other hand, respondents ages 21-34 and those who belonged to households with no member less than age 5 were more likely to use the automated shuttle for some/all of their campus trips (see Table 2).

\section{Table 2 - Binary Logit Model Estimation of Respondents' Likelihood to Use Automated Shuttles for Some/All Campus Trips}

\begin{tabular}{|c|c|c|c|}
\hline Variable Description & Coefficient & t-statistics & $\begin{array}{c}\text { Marginal } \\
\text { Effects }\end{array}$ \\
\hline Constant & 0.522 & 0.86 & \\
\hline \multicolumn{4}{|l|}{ Sociodemographic Variables } \\
\hline $\begin{array}{l}\text { Male Respondent Indicator ( } 1 \text { if respondent identifies as male, } \\
0 \text { otherwise) }\end{array}$ & -0.704 & -2.13 & -0.088 \\
\hline $\begin{array}{l}\text { White Respondent Indicator ( } 1 \text { if respondent identifies as } \\
\text { White, } 0 \text { otherwise) }\end{array}$ & -0.838 & -2.45 & -0.094 \\
\hline $\begin{array}{l}\text { Young Adult Indicator ( } 1 \text { if respondent is age } 21-34,0 \\
\text { otherwise) }\end{array}$ & 0.989 & 2.97 & 0.113 \\
\hline $\begin{array}{l}\text { Low Income Household Indicator ( } 1 \text { if respondent belongs to } \\
\text { household with annual income }<\$ 50,000,0 \text { otherwise) }\end{array}$ & -0.857 & -2.50 & -0.093 \\
\hline $\begin{array}{l}\text { No Child Under Age } 5 \text { Indicator ( } 1 \text { if respondent belongs to a } \\
\text { household with no member under age 5, } 0 \text { otherwise) }\end{array}$ & 1.459 & 2.45 & 0.232 \\
\hline \multicolumn{4}{|l|}{ Familiarity with Automated Vehicles } \\
\hline $\begin{array}{l}\text { Somewhat Familiar Indicator ( } 1 \text { if respondent is } \\
\text { slightly/moderately familiar with automated vehicles, } 0 \\
\text { otherwise) }\end{array}$ & 0.568 & 1.78 & 0.076 \\
\hline \multicolumn{4}{|l|}{ Past Technology Adoption Behavior } \\
\hline $\begin{array}{l}\text { Early Adopter of Technology Indicator ( } 1 \text { if respondent is an } \\
\text { early adopter of technology, } 0 \text { otherwise) }\end{array}$ & 0.945 & 2.96 & 0.113 \\
\hline Log-likelihood at convergence & & -141.830 & \\
\hline Restricted (fixed parameter) log-likelihood & & -161.117 & \\
\hline Number of respondents & & 363 & \\
\hline
\end{tabular}

Apart from demographic differences in the anticipated use of automated shuttles, familiarity and past technology adoption behavior were found to be very highly significant predictors towards 
adoption/non-adoption of automated shuttles on campus. Respondents who had some level of familiarity with AVs before taking part in the demonstration had a positive outlook towards using the automated shuttles on campus. A similar behavior was echoed by respondents who consider themselves to be early adopters of new technology, who can have a significantly positive impact on use of automated shuttles. It is likely that their generally positive and optimistic outlook towards new technology makes them ideal candidates for using automated shuttles when they become available on campus.

Investigating factors that influence respondent willingness to pay, only three fixed parameters were found to be statistically significant (see Table 3). For instance, there were no gender-level differences in respondents' willingness to pay a small monthly/annual fee for using automated shuttles on campus. Respondents age 35 or more at the time of the survey were found to be more likely to be willing to pay a small monthly/annual fee for using the automated shuttle compared to their younger counterparts. It is perhaps expected that the younger demographic displayed slight resistance to pay for new/emerging technologies, especially when the technology is rapidly evolving. Similarly, respondents who identified themselves as Asian were more likely to be willing to pay for the automated shuttle. As witnessed in the previous model for use, past technology adoption behavior plays a crucial role in determining the propensity of respondents to pay for using the automated shuttle; early adopters of technology are significantly more likely to be willing to pay a small monthly/annual fee to use the automated shuttle.

Table 3 - Binary Logit Model Estimation of Respondents' Willingness to Pay to Use Automated Shuttles for Campus Trips

\begin{tabular}{lccc}
\hline \multicolumn{1}{c}{ Variable Description } & Coefficient & $\begin{array}{c}\text { t- } \\
\text { statistics }\end{array}$ & $\begin{array}{c}\text { Marginal } \\
\text { Effects }\end{array}$ \\
\hline $\begin{array}{l}\text { Constant } \\
\text { Sociodemographic Variables }\end{array}$ & -1.015 & -5.23 & \\
$\begin{array}{l}\text { Older Adult Indicator (1 if respondent is age 35 or more, 0 } \\
\text { otherwise) }\end{array}$ & 0.538 & 1.87 & 0.127 \\
$\begin{array}{l}\text { Asian Respondent Indicator (1 if respondent identifies } \\
\text { ethnically as Asian, 0 otherwise) }\end{array}$ & 0.419 & 1.71 & 0.098 \\
$\begin{array}{l}\text { Past Technology Adoption Behavior } \\
\text { Early Adopter of Technology Indicator (1 if respondent is } \\
\text { early adopter of technology, 0 otherwise) }\end{array}$ & 0.655 & 2.93 & 0.151 \\
\hline $\begin{array}{l}\text { Log-likelihood at convergence } \\
\text { Restricted (fixed parameter) log-likelihood }\end{array}$ & & -235.190 & \\
Number of respondents & & -242.882 & \\
\hline
\end{tabular}




\section{Conclusion}

This report summarizes the findings from a week-long AV demonstration held at the University of South Florida Tampa campus in February 2019. Planning a demonstration of this magnitude required relatively high-level coordination among project stakeholders, as documented in this report. Various candidate sites on campus were inspected by the project team. Based on extensive conversations with campus stakeholders and the AV manufacturer, Coast Autonomous, the final selected site for the demonstration was the pedestrian walkway between the USF Library and the USF Recreation Center. Once this final site was selected, the CUTR team determined various methods to assess the automated shuttle demonstration, including an onboard/feedback survey of automated shuttle riders, field observation studies, and CAV expert assessments.

Results from the onboard survey of 500+ riders showed an overwhelmingly positive attitude towards their rider experience during the demonstration and indicated their willingness to use these automated shuttles as a mode for travel on campus. Results from this study also show the potential for AVs to replace some campus trips currently undertaken via other modes. The onboard survey also indicated a growing trust by users exposed to AVs and their subsequent ride in the shuttle.

The field observation studies showed the capability of the automated shuttle to gradually adjust its speed and direction when faced with the prospect of interacting with road users. Depending on the scenario, the shuttle was able to take passive action and avoid conflicts with other road users, a characteristic that was echoed by CAV experts during their assessment. The low-speed nature of the automated shuttle makes it an excellent candidate for application on large campuses such as universities, commercial campuses, hospitals, theme parks, and retirement communities.

Binary logit model estimations were conducted to understand the influence of various sociodemographic factors, familiarity with AVs, and past technology adoption behavior towards respondent use and willingness to pay for automated shuttles on campus. Although the usage model revealed significant gender-level differences in the use of automated shuttles on campus, similar effects were not observed when it came to willingness to pay a small monthly/annual fee. Respondent age and ethnicity were significant predictors in determining the likelihood of using automated shuttles, with ethnicity being a significant influence also in willingness to pay. Familiarity with AVs was a significant in the usage model, but there was no statistical significance for familiarity in their willingness to pay. However, past technology adoption behavior is a significant predictor in understanding potential users and those who are willing to pay for automated shuttles in the future.

Considering the vast market potential for this emerging transportation technology, it would be worthwhile to investigate the role of automation in inducing new travel and substituting existing travel through other modes. A fleet of AVs when set up in a gridded network in past simulationbased studies has already been shown to induce travel behavioral changes and the ability to 
replace/chain trips undertaken by private vehicles. Studies such as the current one provide an opportunity to better understand the potential impacts of these technologies on future travel from a trip-making perspective by providing opportunity to glean such information from actual travelers. It is important to note that studies such as this are an opportunity to discuss how AV technologies can complement the existing travel landscape and provide an additional transportation mode into the choice set. Therefore, it is important to look at the findings from this study in an environment of complementing mobility options, as opposed to a direct competition with options such as walking, and bicycling.

Future studies on this topic could incorporate frameworks to better understand the nature of trip making that is likely to be impacted by AV technologies. Keeping in mind the rapidly evolving nature of AV technology, it is important to approach the results from studies of this nature with some caution. As exposure increases to discussions and discourse surrounding AVs, opinions and preferences towards these technologies are bound to change. Studies and demonstrations such as this, in which respondents are exposed to new/emerging technologies, can serve as important benchmarks to assess the progression of public opinion and preferences towards this technology in a rapidly-evolving world. 


\section{References}

1. Hillsborough County. Imagine 2040: Long Range Transportation Plan. Retrieved from: http://www.planhillsborough.org/2040-lrtp/ (May 30, 2018).

2. Bansal, P., Kockelman, K. M., \& Singh, A. (2016). Assessing public opinions of and interest in new vehicle technologies: An Austin perspective. Transportation Research Part C: Emerging Technologies, 67, 1-14.

3. Menon, N., Pinjari, A. R., Zhang, Y., \& Zou, L. (2016). Consumer perception and intended adoption of autonomous-vehicle technology: Findings from a university population survey. Transportation Research Board 95th Annual Meeting (No. 16-5998).

4. Moore, G. (2002). Crossing the Chasm: Marketing and Selling Disruptive Products to Mainstream Customers. New York: Harper Business.

5. Heffner, R., Kurani, K., Turrentine, T. (2007). Symbolism in California's early market for hybrid electric vehicles. Transportation Research Part D, 12(6), 396-413.

6. Edison, S., Geissler, G. (2003). Measuring attitudes towards general technology: Antecedents, hypotheses and scale development. Journal of Targeting, Measurement and Analysis for Marketing 12(2), 137-156.

7. Sheela, P. V., \& Mannering, F. (2019). The effect of information on changing opinions toward autonomous vehicle adoption: An exploratory analysis. International Journal of Sustainable Transportation, 1-13.

8. Bansal P., Kockelman, K. (2017). Forecasting Americans' long-term adoption of connected and autonomous vehicle technologies. Transportation Research Part A, 95, 49-63.

9. Kyriakidis, M., Happee, R., \& De Winter, J. C. F. (2015). Public opinion on automated driving: Results of an international questionnaire among 5,000 respondents. Transportation Research Part F: Traffic Psychology and Behavior, 32, 127-140.

10. Menon, N., Zhang, Y., Pinjari, A. R., \& Mannering, F. (2020). A statistical analysis of consumers' perceptions towards automated vehicles and their intended adoption. Transportation Planning and Technology, 43(3), 253-278.

11. Regan, M., Cunningham, M., Dixit, V., Horberry, T., Bender, A., Weeratunga, K., \& Hassan, A. (2017). Preliminary findings from the first Australian national survey of public opinion about automated and driverless vehicles. https://www.nrso.ntua.gr/wpcontent/uploads/ADVI-Public-Opinion-Survey-7June2016_Final-for-Circulation-1.pdf. Accessed July 23, 2019.

12. Hyde, S., Dalton, P., \& Stevens, A. (2017). Attitudes to autonomous vehicles (No. PPR823).

https://trl.co.uk/sites/default/files/Attitudes\%20to\%20AV\%20TRL\%20Report_final_PP R823.pdf. Accessed July 21, 2019.

13. Gorris, T., De Kievit, M., Solar, A., Katgerman, J. \& Bekhor, S. (2011). CityMobil. Towards advanced transport for the urban environment (Deliverable D5.4.1, Assessment of Automated Road Transport Systems contribution to Urban Sustainability). 
http://www.citymobil-project.eu/downloadables/Deliverables/D5.4.1-II-PU-

Final\%20ex\%20post\%20report\%20part\%204-CityMobil.pdf. Accessed July 25, 2019.

14. Alessandrini, A. (2016). CityMobil2. Experiences and recommendations.

https://www.polisnetwork.eu/CityMobil2\%20booklet\%20web\%20final_17\%2011\%2020 16.pdf. Accessed July 28, 2019.

15. Madigan, R., Louw, T., Dziennus, M., Schieben, A., \& Merat, N. (2017). What influences the decision to use automated public transport? Using UTAUT to understand public acceptance of Automated Road Transport Systems. Transportation Research Part F: Traffic Psychology and Behavior, 50, 55-64.

16. Portouli, E., Karaseitanidis, G., Lytrivis, P., Amditis, A., Raptis, O. \& Karaberi, C. (2017). Public attitudes towards autonomous mini buses operating in real conditions in a Hellenic city. Proceedings of the 2017 IEEE Intelligent Vehicles Symposium, Los Angeles, CA, 571-576.

17. Eden, G., Nanchen, B., Ramseyer, R., \& Evéquoz, F. (2017). On the road with an autonomous passenger shuttle: Integration in public spaces. Proceedings of the $2017 \mathrm{CHI}$ Conference Extended Abstracts on Human Factors in Computing Systems, ACM, 15691576

18. Pessaro, B. (2016). Evaluation of automated vehicle technology in transit - 2016 update. National Center for Transit Research Report. https://www.nctr.usf.edu/wpcontent/uploads/2016/04/Evaluation-of-Automated-Vehicle-Technology-for-Transit2016-Update-UPDATED-FINAL.pdf (May 11, 2018).

19. Easy Mile Infographics, personal communication (November 29, 2017).

20. NAVYA. (2017). AUTONOM SHUTTLE Technical Specifications. http://navya.tech/wp-content/uploads/2017/11/NAVYA_DP_SHUTTLE_ 2017_GB_SPECIFICATIONS.pdf (March 12, 2018).

21. Local Motors. (2018). Meet Olli. https://localmotors.com/meet-olli/. (March 12, 2018).

22. Tækker, C. (2017). Self-driving bus Olli tested on Lyngby campus. http://www.dtu.dk/english/news/2017/05/self-driving-bus-olli-tested-on-lyngbycampus?id=42bf02e8-3b89-461f-ab19-a10beb1ac6be (April 25, 2018).

23. Coast Autonomous. (2018a). Media Guide. https://static1.squarespace.com/static/ $\underline{\text { 58dbbb2dbebafb6c932fd360/t/5a03252971c10badfd34b3f9/1510155561980/Coast+Med }}$ ia+Guide+2017+1107.pdf (April 25, 2018).

24. Coast Autonomous (2018b). Autonomous Innovation. https://www.coastautonomous.com/ (April 25, 2018).

25. Isaac, L., personal communication (November 30, 2017).

26. Holmes, J., personal communication (March 12, 2018).

27. Chatham, A., personal communication (March 21, 2018).

28. Foster, A., personal communication (February 15, 2018).

29. Schock, T., personal communication (March 23, 2018).

30. Sussmann, A., personal communication (February 21, 2018).

31. Gygi, T., personal communication (April 16, 2018). 
32. Navya, personal communication (March 20, 2018).

33. Chronicle of Higher Education. (2010). Campus Architecture Database: Phyllis P.

Marshall Student Center. https://www.chronicle.com/blogs/buildings/campusarchitecture-database-phyllis-p-marshall-student-center/20921 (June 7, 2018).

34. Hamed, M., Mannering, F.L. (1993). Modeling travelers' post-work activity involvement: Toward a new methodology. Transportation Science, 27(4), 381-394.

35. Young, R.K., Liesman, J. (2007). Estimating the relationship between measured wind speed and overturning truck crashes using a binary logit model. Accident Analysis \& Prevention 39(3), 574-580.

36. Sarwar, M. T., Anastasopoulos, P. C., Ukkusuri, S. V., Murray-Tuite, P., \& Mannering, F. L. (2018). A statistical analysis of the dynamics of household hurricane-evacuation decisions. Transportation, 45(1), 51-70.

37. Train, K. (2003). Discrete Choice Methods with Simulation. Cambridge University Press, Cambridge.

38. McFadden, D. (1981). Econometric models of probabilistic choice. In Manski, C., McFadden, D. (eds.) Structural Analysis of Discrete Data with Econometric Applications. MIT Press, Cambridge.

39. Washington, S.P., Karlaftis, M.G., Mannering, F.L. (2011). Statistical and Econometric Methods for Transportation Data Analysis, 2nd ed. CRC Press, Boca Raton.

40. Greene, W. (2007). LIMDEP Version 9.0. Econometric Software Inc., Plainview 


\section{Appendix A - Onboard Survey Questionnaire}

1. Was this your first-ever ride in an automated vehicle?

$\square$ Yes

$\square$ No

Don't know

2. How familiar were you with automated vehicles before riding the automated shuttle?
$\checkmark$ Not at all familiar
$\square$ Slightly familiar
$\square$ Moderately familiar
Extremely familiar

3. How was your overall experience riding in the automated shuttle?
$\square$ Very uncomfortable
$\square$ Neither uncomfortable nor
Comfortable
$\square$ Uncomfortable
comfortable
$\square$ Very comfortable

4. Based on your ride, what aspects of the campus automated shuttle could be improved? Mark all that apply.

$\square$ Increased feeling of safety

Wi-Fi readability

Increase my level of trust

More conductor interaction $\square$ Better interaction with pedestrians/bicyclists/other vehicles

$\checkmark$ Increased speed of travel

$\square$ Other

5. Please provide your opinion on the following statements if an automated shuttle service were to be available on campus.

\begin{tabular}{|c|c|c|c|c|c|}
\hline & $\begin{array}{l}\text { Extremely } \\
\text { unlikely }\end{array}$ & Unlikely & Unsure & Likely & $\begin{array}{l}\text { Extremely } \\
\text { likely }\end{array}$ \\
\hline $\begin{array}{l}\text { I would use the automated shuttle for some/all } \\
\text { of my campus trips }\end{array}$ & & & & & \\
\hline $\begin{array}{l}\text { If necessary, I would be willing to pay a small } \\
\text { monthly/annual fee to use the automated shuttle } \\
\text { service }\end{array}$ & & & & & \\
\hline $\begin{array}{l}\text { I would be comfortable riding in an automated } \\
\text { shuttle without an operator at all times }\end{array}$ & & & & & \\
\hline $\begin{array}{l}\text { I would trust the automated shuttle to operate } \\
\text { smoothly around pedestrians, bicyclists, and } \\
\text { other vehicles }\end{array}$ & & & & & \\
\hline $\begin{array}{l}\text { I would be comfortable with an automated } \\
\text { shuttle operating through the campus on large } \\
\text { sized sidewalks and walkways (at speeds of 8-10 } \\
\text { mi/hr.) }\end{array}$ & & & & & \\
\hline
\end{tabular}

6. Which of your following campus trip modes would you like an automated shuttle operating on-campus to replace? Choose one for each row

\begin{tabular}{|c|l|l|l|l|l|}
\hline On-campus trips using & Some & All & None & $\begin{array}{c}\text { Don't } \\
\text { know/Can't } \\
\text { Say }\end{array}$ & N/A \\
\hline Walk & & & & & \\
\hline Bike/Campus Bikeshare & & & & & \\
\hline Bull Runner & & & & & \\
\hline Personal Vehicle & & & & & \\
\hline Motorcycle/scooter & & & & & \\
\hline Longboard/skateboard & & & & & \\
\hline
\end{tabular}


7. Generally speaking, would you say that automated shuttles can be trusted to perform all safety-critical driving functions for an entire trip?
Strongly Disagree
$\square$ Unsure
Strongly Agree
Disagree
Agree

8. Has your trust level with automated technology changed after riding the automated shuttle?

$\begin{array}{lll}\square \text { Trust level } & \square \text { Trust level } & \text { Trust level } \\ \text { increased } & \text { decreased } & \text { remains the } \\ & \text { same }\end{array}$

9. What is your most concerning factor about using automated shuttles?

$\begin{array}{lll}\square \text { Safety-related concerns } & \square \text { Higher travel time than my current } & \square \text { Unreliability of the service } \\ \square \text { Privacy-related concerns } & \text { travel time } & \square \text { Cost-related concerns }\end{array}$

10. What is your least concerning factor about using automated shuttles?

$\begin{array}{lll}\square \text { Safety-related concerns } & \square \text { Higher travel time than my current } & \square \text { Unreliability of the service } \\ \square \text { Privacy-related concerns } & \text { travel time } & \square \text { Cost-related concern }\end{array}$

11. What is your gender?
Male
Female

12. Please select your age group
17 or younger
25-34
55-64
$\square$ 18-20
$\square$ 35-44
65 or older
$\square 21-24$
45-54

13. What is your ethnicity?

$\square$ Hispanic or Latino

Not Hispanic or Latino

14. What race do you identify yourself as?

$\begin{array}{lll}\square \text { White } & \square \text { American Indian/Alaska } & \square \text { Native Hawaiian/Pacific } \\ \square \text { Black or African } & \text { Native } & \text { Islander } \\ \text { American } & \square \text { Asian } & \square \text { Other }\end{array}$

15. What is your status at USF?

$\square$ Student (undergraduate/graduate etc.)

Faculty

$\square$ Postdoctoral Fellow/Research Scientist

$\square$ Visitor (visiting scholar, guest etc.)

Staff

Other

16. Which category below indicates your annual household income? (if student away from home, only include personal income)
$\square$ \$0 - \$24,999
$\square \$ 75,000-\$ 99,999$
$\$ 150,000-\$ 174,999$
$\$ 25,000-\$ 49,999$
$\square$ \$100,000 - \$124,999
$\$ 175,000$ - \$199,999
$\$ 50,000-\$ 74,999$
$\$ 125,000-\$ 149,999$
$\$ 200,000$ and above 
17. How many people currently live in your household, including yourself? (if student away from home, only include your present situation)

\begin{tabular}{|l|l|}
\hline Number of children under the age of 5 & \\
\hline Number of children under the age of 16 & \\
\hline Number of children under the age of 18 & \\
\hline Number of members in your household who are 18 or older & \\
\hline
\end{tabular}

18. Please provide information about your typical mode of travel, one-way distance, and one-way travel time to USF (circle over the appropriate options in each row)

\begin{tabular}{|c|c|c|c|c|c|c|c|c|c|}
\hline $\begin{array}{c}\text { Mode of } \\
\text { travel }\end{array}$ & $\begin{array}{l}\text { Drive } \\
\text { Alone }\end{array}$ & $\begin{array}{c}\text { Share ride, } \\
\text { as a driver/ } \\
\text { passenger }\end{array}$ & $\begin{array}{l}\text { Taxi/Cab/ } \\
\text { Uber/Lyft }\end{array}$ & $\begin{array}{l}\text { Campus } \\
\text { shuttle }\end{array}$ & $\begin{array}{l}\text { Public } \\
\text { transit }\end{array}$ & $\begin{array}{l}\text { Longboard/ } \\
\text { Skateboard }\end{array}$ & $\begin{array}{c}\text { Bicycle/ } \\
\text { Campus } \\
\text { bikeshare } \\
\end{array}$ & $\begin{array}{c}\text { Motorcycle/ } \\
\text { scooter }\end{array}$ & Walk \\
\hline $\begin{array}{c}\text { Distance } \\
\text { (one-way) }\end{array}$ & $\begin{array}{l}\text { Less } \\
\text { than } 1 \\
\text { mile }\end{array}$ & 1-3 miles & 3-5 miles & $\begin{array}{l}5-10 \\
\text { miles }\end{array}$ & $\begin{array}{l}10-15 \\
\text { miles }\end{array}$ & $15-20$ miles & $20-30$ miles & $\begin{array}{c}\text { 30-miles or } \\
\text { more }\end{array}$ & \\
\hline $\begin{array}{c}\text { Commute } \\
\text { time } \\
\text { (one-way) }\end{array}$ & $\begin{array}{l}\text { Less } \\
\text { than } 5 \\
\text { mins }\end{array}$ & $5-10$ mins & $10-20$ mins & $\begin{array}{l}20-30 \\
\text { mins }\end{array}$ & $\begin{array}{c}30-45 \\
\text { mins }\end{array}$ & $45-60$ mins & $60-90$ mins & $\begin{array}{l}90 \text { mins or } \\
\text { more }\end{array}$ & \\
\hline
\end{tabular}

19. Have you ever been involved in a traffic crash in the last 3 years?

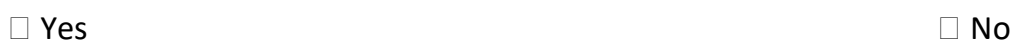

20. How many vehicles (owned and/ or leased) are present in your household? Do not include bicycles. (if student away from home, only include your present situation)
$\square 0$
$\square 1$
$\square 2$
$\square 3$
$\square 4$
$\square$ More than 4

21. When it comes to new technology, what best describes you?

$\square$ I am skeptical of new technologies and use them only when I have to

$\square$ I am usually one of the last people I know to use new technologies

$\square$ I use new technologies when most of the people I know use them

$\square$ I like new technologies and use them before most people I know

$\square$ I love new technologies and am among the first to experiment and use them 


\section{Appendix B - Field Observation Survey}

Date:

Approximate Start Time of Trip:

Approximate End Time of Trip:

Did the autonomous shuttle start smoothly, or with a sudden and uncomfortable start? (AT START)

Start smoothly

Sudden start with longitudinal waggle

Did the autonomous shuttle stop smoothly, or with a sudden and uncomfortable stop? (AT FINISH)

Stop smoothly

Sudden stop with longitudinal waggle

\begin{tabular}{|c|c|c|c|c|}
\hline Event & Shuttle Reaction & Pedestrian Reaction & Bicyclist Reaction & Skateboarder Reaction \\
\hline & & & & \\
\hline & & & & \\
\hline & & & & \\
\hline & & & & \\
\hline & & & & \\
\hline & & & & \\
\hline & & & & \\
\hline & & & & \\
\hline & & & & \\
\hline & & & & \\
\hline & & & & \\
\hline & & & & \\
\hline & & & & \\
\hline
\end{tabular}

\section{Event Type:}

1. Pedestrian(s) along the same direction of the shuttle (on one side)

2. Pedestrian(s) along the same direction of the shuttle (on both sides)

3. Pedestrian(s) along the same direction of the shuttle (in front)

4. Pedestrian(s) along the opposite direction of the shuttle (on one side)

5. Pedestrian(s) along the opposite direction of the shuttle (on both sides)

6. Pedestrian(s) along the opposite direction of the shuttle (in front) 
7. Bicyclist(s) along the same direction of the shuttle (on one side)

8. Bicyclist(s) along the same direction of the shuttle (on both sides)

9. Bicyclist(s) along the same direction of the shuttle (in front)

10. Bicyclist(s) along the opposite direction of the shuttle (on one side)

11. Bicyclist(s) along the opposite direction of the shuttle (on both sides)

12. Bicyclist(s) along the opposite direction of the shuttle (in front)

13. Skateboarder(s) along the same direction of the shuttle (on one side)

14. Skateboarder(s) along the same direction of the shuttle (on both sides)

15. Skateboarder(s) along the same direction of the shuttle (in front)

16. Skateboarder(s) along the opposite direction of the shuttle (on one side)

17. Skateboarder(s) along the opposite direction of the shuttle (on both sides)

18. Skateboarder(s) along the opposite direction of the shuttle (in front)

19. Obstacles (such as leaves, branches, twigs) on the walkway

20. Other (make a note)

\section{Shuttle Reactions:}

1. Shuttle gradually adjusts its speed and continues its trip

2. Shuttle gradually adjusts its direction and continues its trip

3. Shuttle gradually comes to a halt along its path (no change in direction)

4. Shuttle gradually comes to a halt after changing its direction

5. Shuttle makes sudden deceleration and/or stop along its path (no change in direction)

6. Shuttle makes sudden deceleration and/or stop after changing its direction

7. Shuttle ignores and maintains the same running status (will crash if it does not stop soon)

8. Other (make a note)

\section{Pedestrian Reactions:}

1. Pedestrian(s) unaware of the shuttle

2. Pedestrian(s) aware of the shuttle and keep moving the same way

3. Pedestrian(s) aware of the shuttle and move away from it

4. Pedestrian(s) cross the walkway in front of shuttle with some distance to the shuttle

5. Pedestrian(s) cross the walkway in front of shuttle with a close distance

6. Other (make a note)

\section{Bicyclist Reactions:}

1. Bicyclist(s) unaware of the shuttle

2. Bicyclist(s) aware of the shuttle and keep moving the same way

3. Bicyclist(s) aware of the shuttle and move away from it

4. Bicyclist(s) cross the walkway in front of shuttle with some distance to the shuttle

5. Bicyclist(s) cross the walkway in front of shuttle with a close distance

6. Other (make a note)

\section{Skateboarder Reactions:}

1. Skateboarder(s) unaware of the shuttle

2. Skateboarder(s) aware of the shuttle and keep moving the same way

3. Skateboarder(s) aware of the shuttle and move away from it

4. Skateboarder(s) cross the walkway in front of shuttle with some distance to the shuttle

5. Skateboarder(s) cross the walkway in front of shuttle with a close distance

6. Other (make a note) 